\title{
Histological variants of urothelial carcinoma: diagnostic, therapeutic and prognostic implications
}

\author{
Mahul B Amin \\ Department of Pathology and Laboratory Medicine, Cedars-Sinai Medical Center, Los Angeles, CA, USA
}

\begin{abstract}
It is well established that invasive urothelial carcinoma, involving the urinary bladder and renal pelvis, has marked propensity for divergent differentiation. In recent years, several 'variant' morphologies have been described and most have been recognized in the 2004 World Health Organization Classification. These histological variants of urothelial carcinoma have clinical significance at various levels, including diagnostic, that is, awareness of the morphological variant is essential in order to avoid diagnostic misinterpretations; prognostic for patient risk stratification; and therapeutic, where a diagnostic assignment of a particular variant may be associated with the administration of a therapy distinctive from that used in conventional invasive urothelial carcinoma. The diagnoses of micropapillary urothelial carcinoma, small-cell carcinoma, lymphoepithelioma-like carcinoma and sarcomatoid carcinoma are prime examples where treatment protocols may be different than the usual muscle-invasive bladder cancer. This review discusses the variants of urothelial carcinoma, outlining for each the diagnostic features, differential diagnostic considerations and the clinical significance.
\end{abstract}

Modern Pathology (2009) 22, S96-S118; doi:10.1038/modpathol.2009.26

Keywords: urothelial carcinoma; variants; nested; small tubules; plasmacytoid; rhabdoid; osteoclast-rich; lymphoepithelioma-like; small cell; large-cell neuroendocrine carcinoma; microcystic carcinoma; sarcomatoid carcinoma; clear cell features; lipoid-rich

Urothelial neoplasms of the urinary bladder may be subdivided into papillary (papillomas, low malignant potential and papillary carcinoma) and non-papillary (urothelial carcinoma in situ and invasive) categories. Papillary tumors are predominantly exophytic, with papillae containing welldefined fibrovascular cores. The lining urothelium may vary from one that is indistinguishable from normal (papilloma) to markedly anaplastic (high-grade urothelial carcinoma). The flat lesion of urothelial carcinoma in situ is characterized by extensive (often full thickness) replacement of the urothelium by cells showing severe cytologic atypia. Invasive urothelial carcinoma cystoscopically and grossly may present as a polypoid, sessile, fungating ulcerated and/or infiltrative lesion, in which the neoplastic cells invade the bladder wall as nests, cords, trabeculae, small clusters or single cells that

Correspondence: Dr MB Amin, MD, Department of Pathology and Laboratory Medicine, Cedars-Sinai Medical Center, 8700 Beverly Blvd. Suite 8728, Los Angeles, California 90048, USA.

E-mail: aminm@cshs.org

Received 6 February 2009; accepted 6 February 2009 are usually separated by a desmoplastic stroma. The tumor sometimes grows in a more diffuse pattern, but even in these cases a focal nested or trabecular architecture is generally present. There is often a variable desmoplastic response and an inflammatory infiltrate; sometimes, there is also a pronounced chronic inflammatory cell infiltrate, which may partially or substantially obscure the underlying tumor cells. The neoplastic cells in these typical or conventional patterns of invasive urothelial carcinoma are usually of moderate to large size and have modest amounts of pale to eosinophilic cytoplasm (Figure 1). In some tumors, the cytoplasm is more abundant and may be clear or strikingly eosinophilic. Nuclear atypia is obvious and some cases may have bizarre hyperchromatic nuclei with marked anaplasia. Features indicative of the urothelial or transitional character of cells of urothelial carcinoma include the presence of longitudinal nuclear grooves that are often appreciable usually only in low-grade tumors, but are absent to only focally present in high-grade tumors (Figure 1). Lymphatic or vascular invasion is seen in varying degrees but is occasionally striking. 


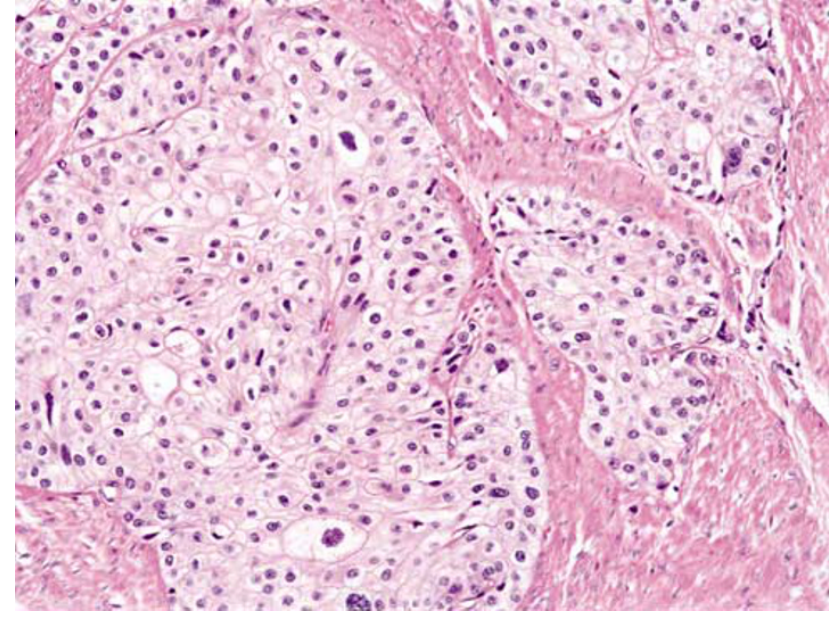

Figure 1 Invasive urothelial carcinoma. This is an example of the typical or garden variety case. Note some of the nuclei have nuclear grooves.

\section{Variants of Urothelial Carcinoma}

The term 'variant' is used to describe a distinctively different histomorphologic phenotype of a certain type of neoplasm. ${ }^{1-5}$ In recent years, as a result of increasing experience with urothelial carcinomas, the spectrum of microscopic forms of urothelial carcinoma has been expanded to include several unusual histological variants. The recognition of histological variants in urothelial neoplasia is important because (a) some types may be associated with a different clinical outcome, (b) some may have a different therapeutic approach or (c) awareness of the unusual pattern may be critical in avoiding diagnostic misinterpretations. ${ }^{1,3}$ Two general rules are recommended when potentially dealing with histological variants: first, the 'variant' histology should be documented in the pathology reports because metastatic tumors usually continue to exhibit the distinctive histological pattern, and knowledge of the variant histology facilitates the association of metastasis with the primary tumor; second, as the pattern of the neoplasm deviates from the more typical histology, the possibility that this 'unusual' morphology represents a metastasis or a secondary involvement from an adjacent malignancy should always be considered and ruled out. Table 1 is a working classification of urothelial carcinoma and its variants, and is derived from earlier publications in this area. ${ }^{1,6}$ Most of these neoplasms and variants have also been recognized by the recent World Health Organization (WHO, 2004) blue book. ${ }^{1,6}$ A single large series has documented that histological variants are common in high-grade urothelial carcinomas of the renal pelvis and that comprised $40 \%$ of the cases in the series. ${ }^{7}$ These authors reported that after squamous and glandular differentiation, sarcomatoid (7\%) and micropapillary $(3.7 \%)$ variants were the most common. These reported figures for the prevalence of variant histology in bladder neoplasia are considerably high on the basis of my personal experience. Similar data are not available in large series reported in the urinary bladder, and therefore the frequency of the different histological variants with respect to the conventional or usual urothelial carcinoma is unavailable.

\section{Urothelial carcinoma with squamous and glandular diffentiation}

Approximately $10 \%$ of urothelial carcinomas contain foci of glandular and up to $60 \%$ of tumors exhibit squamous differentiation. ${ }^{8}$ The actual frequency varies, as this information is not consistently recorded by pathologists. Glandular differentiation is usually in the form of small tubular or gland-like spaces in conventional urothelial carcinoma (urothelial carcinoma with gland-like lumina (Figure 2)) or as a histology similar to enteric adenocarcinoma. Rarely, a coexistent signet ring cell or a mucinous component may be present. To designate squamous differentiation, one must see clear-cut evidence of squamous production (intracellular keratin, intercellular bridges or keratin pearls), and the degree of squamous differentiation, when present, parallels the grade of the urothelial carcinoma. In general, urothelial carcinomas have a relatively nondescript appearance, which when viewed in isolation cannot be differentiated readily from poorly differentiated carcinomas of other types. Therefore, the presence of squamous and/or glandular differentiation in a poorly differentiated neoplasm at a metastatic site should suggest the possibility of urothelial differentiation among other tumors, such as lung and pancreatic tumors, where this is also likely. A pure histology of squamous or adenocarcinoma should ideally be designated as a pure squamous or adenocarcinoma of the bladder. A recent study has shown polysomic signal patterns by fluorescence in situ hybridization in squamous and adenocarcinoma of the bladder using UroVysion probes. ${ }^{9}$ The prognostic significance of squamous or glandular differentiation is unclear, although some studies have suggested an adverse outcome. ${ }^{5,10-12}$ This difference in prognosis may not be apparent when corrected for stage of the disease. Some studies have shown poor response to chemotherapy or radiation therapy, but it is unclear whether the poor response is a reflection of histology or the advanced stage of the disease. ${ }^{8}$

\section{Carcinomas with deceptively bland features}

The vast majority of invasive urothelial carcinomas of the bladder and upper tract are diagnostically relatively straightforward from the histological characterization perspective because of the obvious cytologic atypia and infiltrative growth. In recent years, there has been an increased attention on subtle 
Table 1 Classification of urothelial (transitional cell) neoplasms including variants of urothelial carcinoma

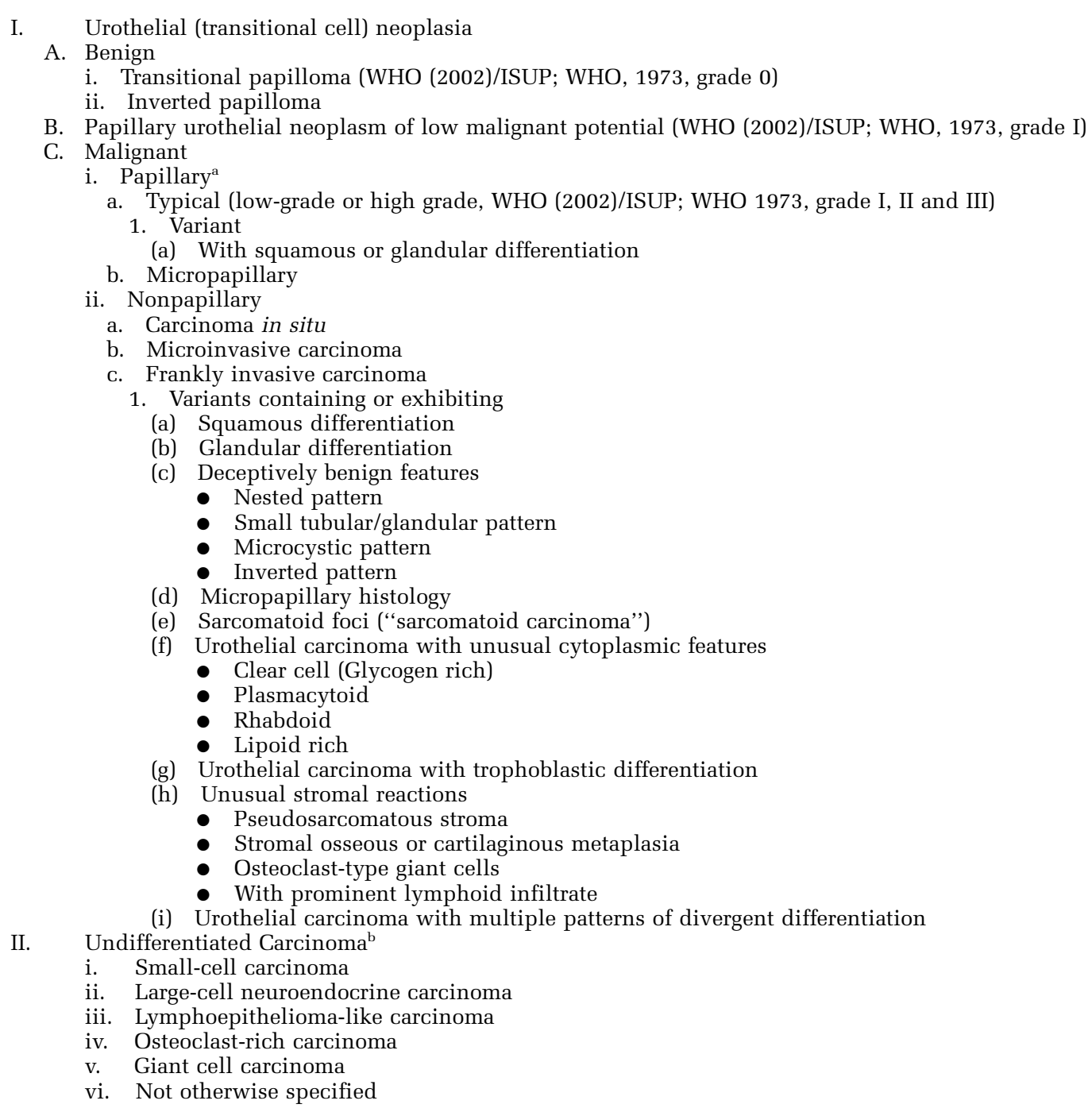

${ }^{\text {a }}$ Papillary tumors may be invasive or noninvasive, and when invasive may be microinvasive (invasive to a depth of $2 \mathrm{~mm}$ or less) or frankly invasive (such as, non-papillary tumors).

$\mathrm{b}_{\text {Tumors that }}$ are undifferentiated by light microscopy.

Table modified from references. ${ }^{1,3,5,6}$

forms of cancer, which may be underdiagnosed either because of their relatively innocuous cytological features or because of their striking similarity to the slightly more commonly occurring benign proliferations in the urinary bladder. Dr Young and colleagues $^{13,14}$ have pointed out that to appreciate these subtle and diagnostically difficult small groups of tumors, it is important to recognize that these tumors re-capitulate what is seen in various benign lesions. The homology between the neoplastic and non-neoplastic lesions modified from their original observations is summarized in Table $2 .{ }^{14-16}$

\section{Nested Variant of Urothelial Carcinoma}

From a pathologist's perspective, the nested variant should appropriately be recognized as a malignant process, particularly in superficial biopsies. Approximately $60-70$ cases have been reported, most as case reports. ${ }^{17-22}$ This variant has distinct patterns in the superficial and deep portions. In biopsy samples and transurethral resectates, the superficial component appears as discrete nests, occasionally with tubules. The nests are tightly packed, often confluent and haphazardly arranged with variable intervening stroma (Figure 3a and b; Tables 2 and 3). Most nests have a relatively bland cytological appearance, but at least some have a greater degree of cytologic atypia. In the deeper portion, the neoplasm usually shows greater cytologic atypia and an irregular infiltrative pattern or obvious muscularis propria invasion. In some tumors, there may be an admixed relatively prominent tubular or small glandular histology. 
The main differential diagnosis is von Brunn's nests. ${ }^{16}$ The best distinguishing feature is that von Brunn's nests extend to a uniform level within the

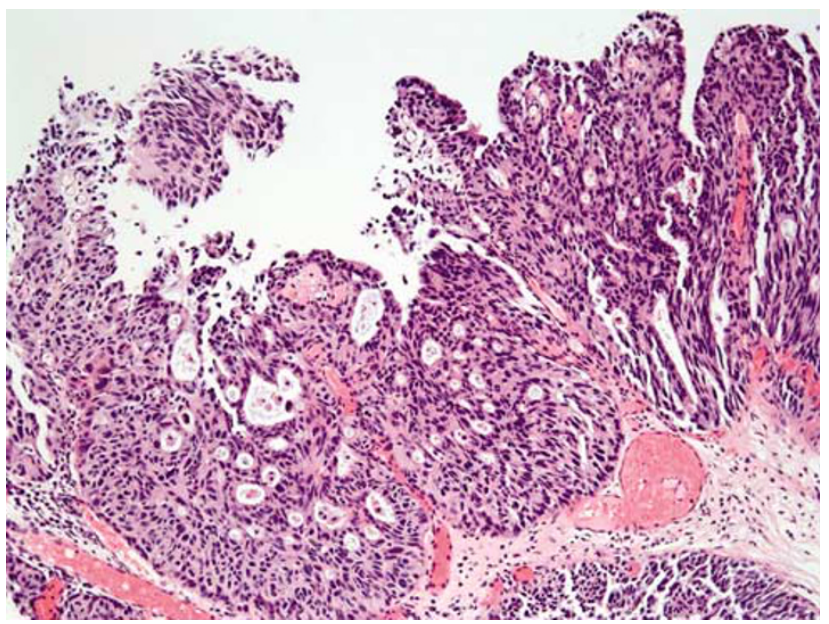

Figure 2 Urothelial carcinoma with glandular differentiation.

Table 2 Similarities between neoplastic and non-neoplastic lesions based on architecture*

\begin{tabular}{|c|c|c|}
\hline Feature & $\begin{array}{l}\text { Variant of urothelial } \\
\text { cancer }\end{array}$ & $\begin{array}{l}\text { Benign lesion } \\
\text { mimicked }\end{array}$ \\
\hline Nests & Nested variant & von Brunn's nests \\
\hline Small tubules & $\begin{array}{l}\text { U.Ca with small } \\
\text { tubules }\end{array}$ & $\begin{array}{l}\text { Nephrogenic } \\
\text { adenoma }\end{array}$ \\
\hline $\begin{array}{l}\text { Medium tubules, } \\
\text { glands and cysts }\end{array}$ & Microcystic variant & $\begin{array}{l}\text { Cystitis cystica and } \\
\text { glandularis }\end{array}$ \\
\hline Inverted growth & Inverted U.Ca & Inverted papilloma \\
\hline $\begin{array}{l}\text { Clefted and long } \\
\text { trabeculae }\end{array}$ & $\begin{array}{l}\text { U.Ca with } \\
\text { deceptively benign } \\
\text { features }\end{array}$ & $\begin{array}{l}\text { Post-radiation } \\
\text { pseudocarcino- } \\
\text { matous } \\
\text { hyperplasia }\end{array}$ \\
\hline
\end{tabular}

U.Ca, Urothelial carcinoma.

${ }^{*}$ Modified from reference 14.

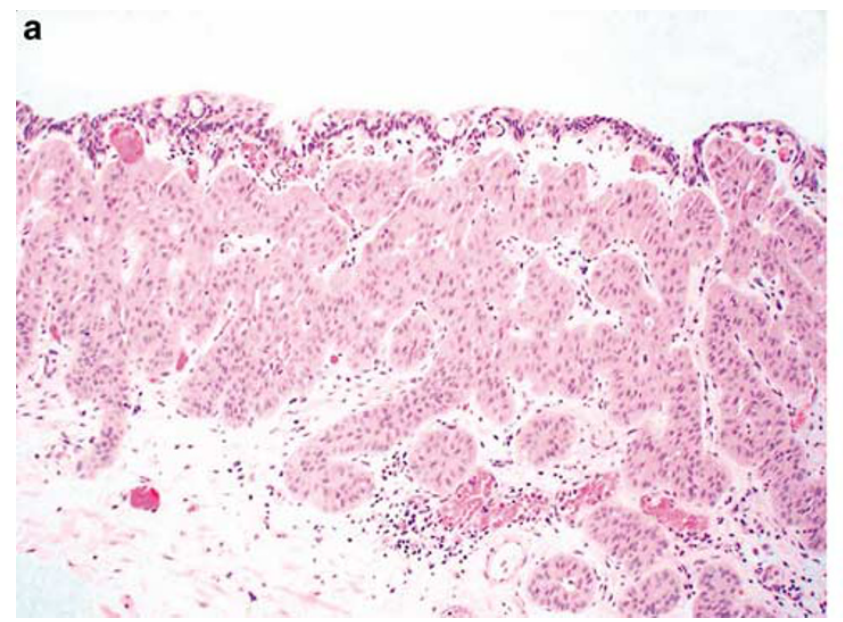

lamina propria, creating a sharp, linear border at the base, which contrasts with the irregular, infiltrative base of nested carcinoma. This aspect may not be determinable or not particularly well appreciated in small superficial biopsies. Other subtle features of invasion may be seen in nested carcinomas such as small clusters or individual neoplastic cells with surrounding retraction artifact. Architectural complexity, confluence and anastomosis between the nests are particularly helpful in distinguishing carcinoma from von Brunn's nests or other benign conditions. Nested carcinomas have small, irregularly sized and contoured, unevenly distributed nests creating confluent, branching patterns, whereas von Brunn's nests are often clustered, evenly and predictably spaced, and round. In the ureter and renal pelvis where it is more common to find von Brunn's nests, the nests tend to be smaller and more irregular, but they still have a lobular or linear arrangement with a sharp border at the base. Invasion of the muscularis propria, despite the bland nuclear features, is diagnostic of carcinoma and is the most definitive distinguishing feature. Unfortunately, in some superficial biopsies or those complicated by extensive cautery artifact, it may be difficult to categorize lesions as unequivocally benign or malignant. In such cases, it is important to correlate the microscopic findings with the clinical impression of the urologist, as the presence of a mass lesion would indicate the need for additional sampling to ascertain for the presence of a more aggressive lesion.

Nephrogenic adenoma with a nested or a tubular pattern may also enter the differential, as it sometimes has a more irregular border and deeper location. ${ }^{23}$ Admixed nested, tubular, cystic, polypoid, papillary and sometimes solid architecture within the same lesion is very characteristic of nephrogenic adenoma and is a helpful feature. Another helpful feature is the edematous and sometimes inflammatory background. The tubules

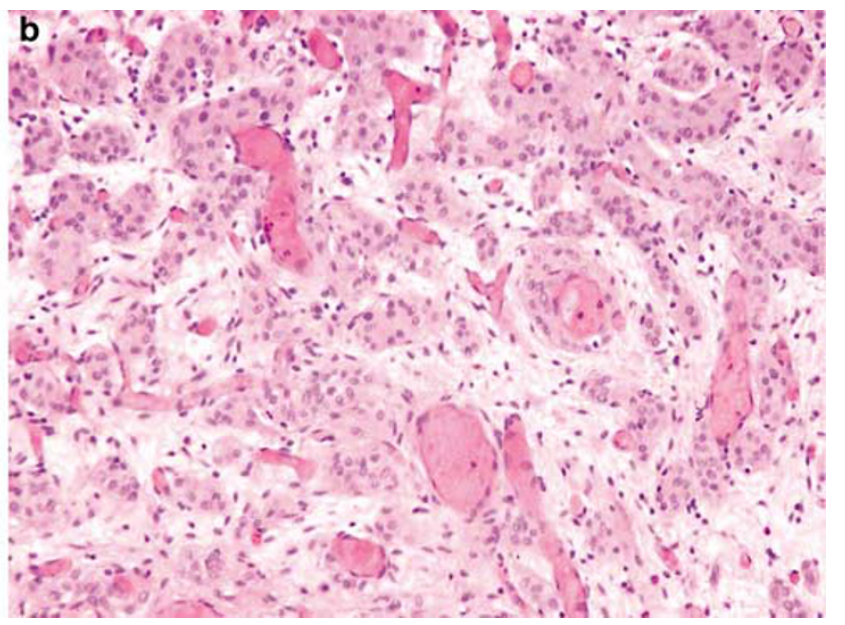

Figure 3 Nested variant of urothelial carcinoma. (a) Low power of complex nests in the superficial lamina propria. (b) The nests are haphazardly arranged, irregular in size and shape, and have no particular orientation to the overlying urothelium. 
Table 3 Neoplasms involving urinary bladder with nested morphology: expected immunophenotypes

\begin{tabular}{lcccc}
\hline & Urothelial cancer & Paraganglioma & Prostate cancer & Carcinoid \\
\hline CK AE1/3 & + & - & + & + \\
Synaptophysin & - & + & + & \pm \\
Chromogranin & - & Sustentacular cells only & + & + \\
S-100 protein & - & - & + & + \\
PSA/PSAP & & & - & + \\
\hline
\end{tabular}
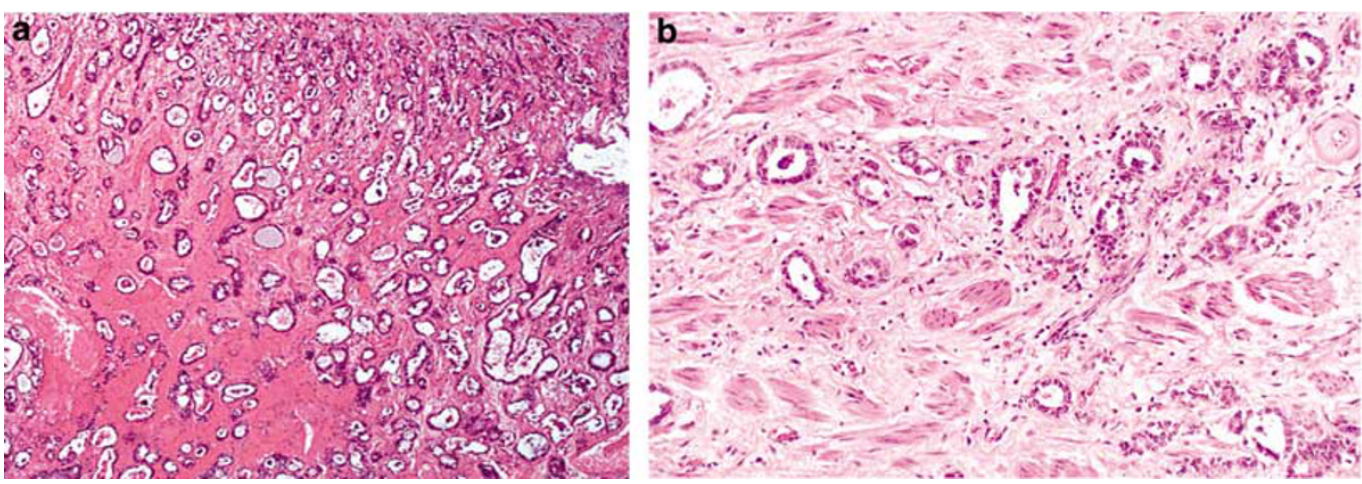

Figure 4 Urothelial carcinoma with small tubules. (a) Transurethral specimen section showing widely invasive carcinoma with distinctive morphology. (b) High power with 'low-grade' nuclear features and invasion in to muscularis propria.

of nephrogenic adenoma are lined by a single cell layer of cuboidal, columnar or flattened cells, as opposed to the typically stratified urothelial layer or solid nests of nested carcinomas. Sometimes, the tubules of nephrogenic adenoma have a prominent basement membrane, which is a very useful clue, if present. Rare cases of nephrogenic adenoma are reported with superficial extension into the muscularis propria, but attention to the constellation of features in nephrogenic adenoma is important to make the distinction from nested variant.

Several other tumors primarily or secondarily involving the urinary bladder may have a nested pattern, including paraganglioma, carcinoid tumor, prostatic adenocarcinoma, melanoma and alveolar soft part sarcoma. In this differential diagnostic context, once the diagnosis of neoplasia is made, the issue is the distinction of urothelial vs non-urothelial nature of the different nested tumors and their distinction from one another using an appropriately constructed immunohistochemical panel. Immunohistochemical studies indicate that the nested variant shares many characteristics with invasive urothelial carcinoma including positivity for cytokeratins 7 and 20, and for p63 and high-molecular-weight cytokeratin. ${ }^{5,17,20,24}$ The nested variant shows loss or the absence of immunoreactivity for cyclin-dependent kinase inhibitors p21 and p27, and positivity for tumor suppressor gene p53, which have been associated with poor prognosis in conventional urothelial carcinoma. $^{20}$ There have been studies supporting MIB-1 as a useful marker in the distinction from benign proliferative lesions, although it must be noted that some cases of nested variant may have low MIB-1 proliferation index and some proliferative lesions may have higher rates. ${ }^{20,25}$ This variability and range of immunostaining for MIB-1 have precluded the author from using MIB-1 immunohistochemistry as a diagnostic adjunct in my practice for such cases.

Data on outcome are confounded by the very small number of reported cases, the variable followup period, differing treatment strategies and importantly lack of prospective comparative analyses within large series of usual and unusual urothelial carcinoma. Information from a few larger case studies on nested variant indicates that many of these patients have an aggressive clinical course characterized by progressive disease, metastasis and death underscoring the importance of recognizing this variant in limited or superficial biopsies and distinguishing it from its many benign mimics..$^{3,17-22}$

\section{Urothelial Carcinoma with Small Tubules}

Although a prominent tubular component may accompany a nested carcinoma, some urothelial carcinomas may have an almost exclusive component of small- to medium-sized, round to elongated tubules that may be misdiagnosed as nephrogenic adenoma or cystitis glandularis (Figure 4a and b). ${ }^{13,14}$ The differential diagnosis with an extension of a prostatic carcinoma is often also a consideration but easily handled by immunohistochemistry (PSA, PSAP: positive in prostate cancer; CK 20, high-molecular-weight cytokeratin; and p63: positive in more than half of urothelial carcinomas). ${ }^{26}$ Furthermore, the tubules of urothelial 
carcinoma are lined by attenuated urothelial cells in contrast to the varying admixture of cuboidal, columnar and occasionally flattened cells that line the tubules of nephrogenic adenoma. Urothelial carcinoma with small tubules may be widely invasive in spite of their deceptively bland histology. The biological significance of this pattern is unclear given the rarity of cases, but some of these cases occur in conjunction with the nested pattern and are widely invasive and have an aggressive outcome because of their high stage. Similar to the nested variant, the chief reason for the awareness of this morphological variant of urothelial carcinoma is not to mistake it in superficial biopsies as a benign glandular proliferative lesion.

\section{Microcystic Urothelial Carcinoma}

This deceptively benign form of urothelial carcinoma is exemplified by the formation of numerous microcysts, which may lead to the misdiagnosis of cystitis cystica. First described by Young and Zukerberg in $1991,{ }^{27-29}$ only $<20$ cases have been reported. The pattern is characterized by a prominent widespread cystic change within nests of urothelial carcinoma or urothelial carcinoma with glandular differentiation (Figure $5 \mathrm{a}$ and $\mathrm{b}$ ). The cysts are round to oval or slit-like, sometimes measuring 1-2 mm and contain secretions that may be targetoid; occasionally they may be calcified. The cyst lining is primarily urothelial interspersed variably by glandular morphology; larger cysts may possess a flattened epithelium or a denuded lining. An innocuous cytology is present by definition, and the most critical feature in distinguishing this carcinoma type from benign conditions is the variation, often dramatic, in size and shape of the epithelial formations and the relatively haphazard random infiltrative growth into the wall of the urinary bladder. Adding to the diagnostic difficulty is the lack of a stromal response or sometimes the presence of a myxoid stroma in the neoplasm.

The chief differential diagnostic considerations are from cystitis cystica, cystitis cystica glandularis and nephrogenic adenoma, which overall tend to have a very organized appearance and lack the overt size variation that typifies microcystic carcinoma. There is no apparent or striking biological significance associated with this pattern of urothelial carcinoma, except that it represents a potentially serious diagnostic pitfall, particularly in limited samples.

\section{Inverted Pattern of Urothelial Carcinoma}

This is not a variant of bladder cancer in the most classic and pure use of the term, but is included here briefly as it falls into the category of bladder carcinoma with deceptively benign features. ${ }^{30,31}$ This form of urothelial carcinoma is associated with two diagnostic challenges: (1) distinction from inverted papilloma and (2) difficulty in assessing invasion. Distinction from the inverted papilloma requires attention to both the architectural and cytological features of the lesion. Urothelial carcinomas with inverted growth usually have thicker columns, with irregularity in width of the columns and/or transition of cords and columns into more solid areas (Figure 6a). The characteristic orderly maturation, spindling and peripheral palisading seen in inverted papilloma is generally absent or inconspicuous in urothelial carcinomas with inverted growth. Unequivocal stromal invasion into the lamina propria or muscularis propria rules out the diagnosis of inverted papilloma. Furthermore, cytologic atypia is an important feature for the diagnosis of carcinoma; and once this distinction is made, carcinomas with inverted growth, similar to their exophytic counterparts, may be classified as low grade or high grade (Figure 6a). Although the endophytic or deeppenetrating growth into the lamina propria caused by the inverted pattern may cause concern for the
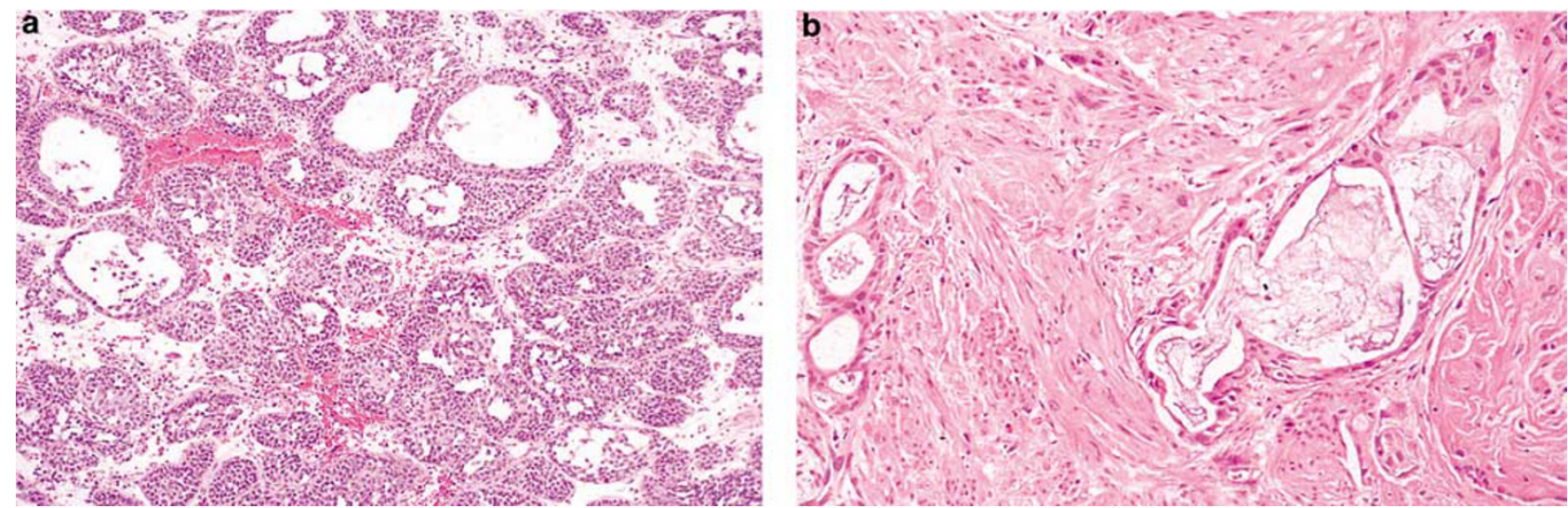

Figure 5 Microcystic urothelial carcinoma. (a) Urothelial carcinoma with variably sized prominent cystic change within carcinoma. (b) High power with 'low-grade' nuclear features and invasion into muscularis propria. 

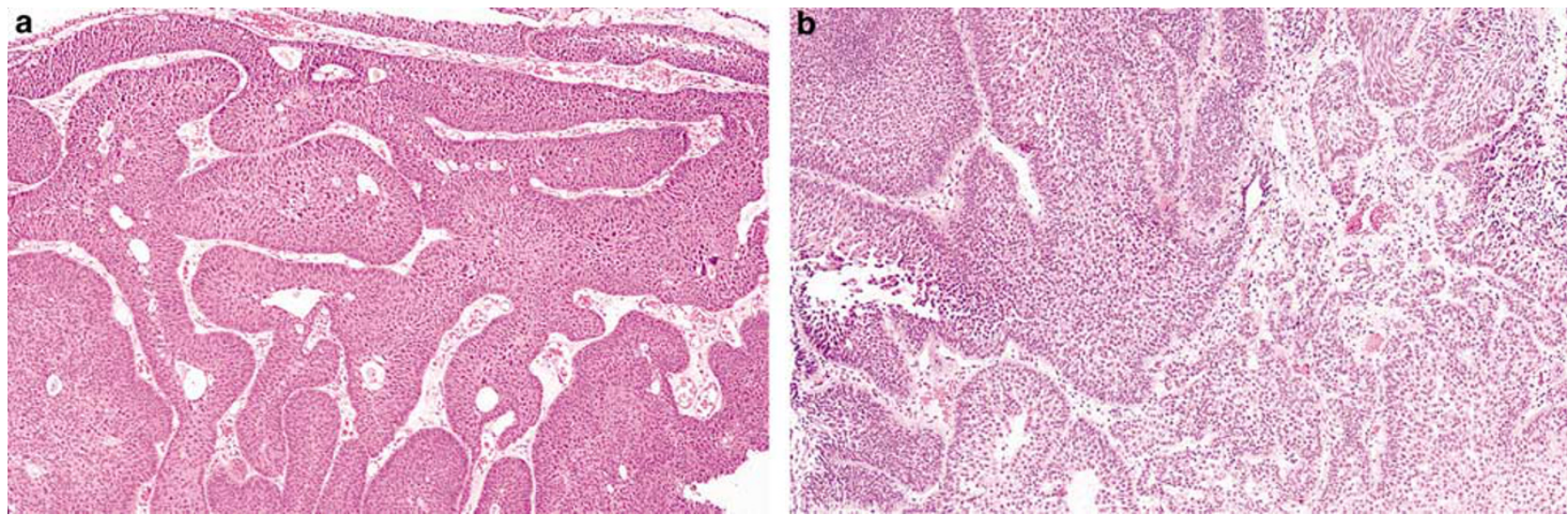

Figure 6 Inverted pattern of urothelial carcinoma. (a) Noninvasive high-grade carcinoma. The surface does not show papillary features. Irregular trabeculae expand the lamina propria in a nondestructive manner. (b) Invasive urothelial carcinoma (right side) with noninvasive inverted component (left side).

presence of invasion, similar to conventional urothelial carcinoma, unequivocal stromal invasion must be present for a neoplasm to be considered invasive. To diagnose stromal invasion, the author recommends that one should insist on the unquestionable presence of irregularly shaped nests or single cells, along with a desmoplastic and/or inflammatory response (Figure 6b) ${ }^{31}$ If a stromal response is absent, marked irregularity of the contours of the nests in question, architectural complexity and the presence of single cell invasion is helpful. Recognition of architectural abnormality, even subtle forms, is important, particularly in the deceptively bland patterns because they are most often cytologically banal. Another clue to recognize invasion is the presence of tumor cells within retraction spaces, which mimic vascular invasion. Early or limited invasion very frequently shows retraction artifact and, in this instance, this feature should not be overcalled as vascular invasion. Although the distinction of inverted papilloma vs carcinoma is usually on the basis of routine light microscopic evaluation, a study has investigated and proposed a role for ancillary techniques including immunohistochemistry (p53, Ki-67, CK 20; all show statistically significant higher expression in carcinomas as compared with that in urothelial papillomas) and UroVysion fluorescence in situ hybridization studies (chromosomal abnormalities absent in urothelial papilloma and present in urothelial carcinoma). ${ }^{32}$

\section{Micropapillary variant of urothelial carcinoma}

Approximately 120 cases of this variant have been reported since the first description of a series of cases in the urinary bladder in $1994 .^{7,33-43}$ This rare histological variant comprises $0.6-1 \%$ of urothelial carcinomas and shows a definite male predominance (male to female ratio, 5:1-10:1), which is higher than in conventional urothelial carcinoma (3:1). This histological variant of urothelial carcinoma has a micropapillary architecture, which is reminiscent of the papillary configuration seen in ovarian papillary serous tumors (Figure $7 \mathrm{a}$ and b). ${ }^{40}$ The majority of tumors are muscle invasive at the time of presentation. Histologically, the micropapillary component of these tumors may be encountered in the (a) noninvasive component, (b) invasive component and (c) in metastasis. This pattern may be focal, extensive $(>90 \%)$ or exclusive. The percentage of micropapillary component has been shown to be a significant adverse prognostic factor. There is no specified criterion required to designate a case as micropapillary carcinoma, and most series in the literature have included cases with $<10 \%$ to almost pure micropapillary histology. The author personally diagnoses cases specifying the percentage of micropapillary histology using terminology such as 'Urothelial carcinoma, high grade, with micropapillary histo$\operatorname{logy}(30 \%)$ and invasion into muscularis propria (at least pT2 disease); accompanying urothelial carcinoma in situ, non-papillary mucosa'.

Urothelial carcinoma in situ is demonstrable in $>50 \%$ of the cases and concurrent glandular differentiation is known to occur; an exquisitely rare case with admixed trophoblastic differentiation has also been reported. ${ }^{43}$ The following five histological features of the micropapillary component are noteworthy: (i) The micropapillary histology has two distinct patterns; on the surface it forms slender, delicate filiform processes rarely with a fibrovascular core. When cut in cross-sections, these papillae appear as glomeruloid bodies. In the invasive component and in all metastatic sites, the tumor cells are arranged in small tight nests or balls. (ii) Psammoma bodies, a feature of ovarian papillary serous neoplasia, are exquisitely rare. (iii) The tumor cells in the invasive and metastatic components are aggregated in lacunae or stromal retraction spaces, which mimic vascular invasion. ${ }^{40}$ This feature is intriguing and extremely characteristic of 

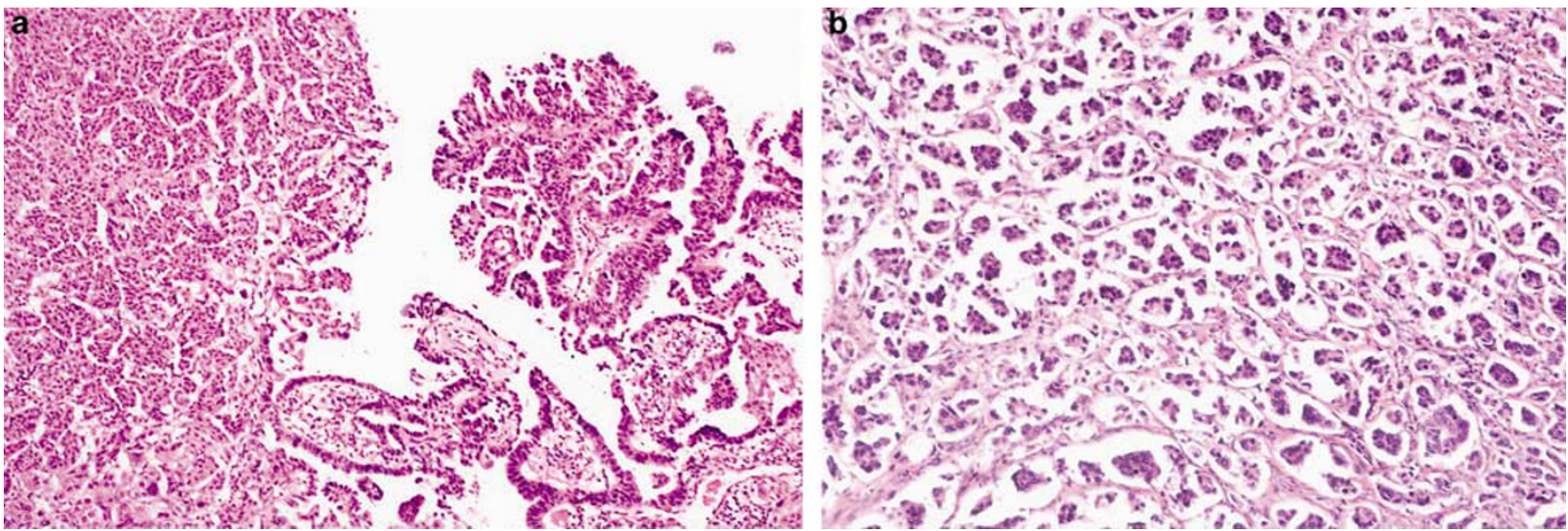

Figure 7 Micropapillary variant of urothelial carcinoma. (a) Noninvasive micropapillary component (right side) and invasive carcinoma in lamina propria (left side). (b) Tight nests of urothelial cells are surrounded by a typical retraction artifact.

the invasive micropapillary carcinoma. The spaces may be lined focally by flattened spindled cells or may be devoid of any lining. In most instances, there is no host response to the tumor cells that merely seem to occupy hollow spaces at various random intervals within the tumor. This pattern of lacunae containing neoplastic cells is also seen in the metastatic sites. (iv) The micropapillary carcinoma always shows a high nuclear grade (high grade by the WHO/ISUP classification), although some areas within a neoplasm may parallel low-grade urothelial carcinoma. (v) Finally, vascular-lymphatic invasion is present in more than half of muscle invasive micropapillary carcinomas, if one looks for it carefully. A high frequency has been confirmed by CD 31 (endothelial marker) and D2-40 (lymphatic endothelial marker). ${ }^{5}$ Awareness that lacunae of micropapillary urothelial carcinoma may mimic vascularlymphatic invasion is important so as not to overdiagnose the presence of this feature, which is considered to be an ominous sign in invasive urothelial carcinoma regardless of the stage of disease.

The main differential diagnosis in women is with a metastatic papillary serous carcinoma, especially if the tumor is originally discovered in the peritoneum, abdominal lymph nodes and mesentery or as a carcinoma of unknown origin. Carcinomas with micropapillary histology have also been reported in the lung, breast, pancreas and salivary glands. Clinical/radiographic correlation is usually required, but the possibility of a bladder primary may be suggested if there is no obvious primary tumor at another anatomic site. Identification of an admixed urothelial carcinoma of more typical morphology or immunohistochemical support (CK 7, CK 20 and uroplakin III positivity) would be helpful. ${ }^{42,44}$ In a bladder tumor, pure micropapillary histology may raise concern for a primary adenocarcinoma of the bladder; however, the micropapillary architecture is due to neoplastic urothelial cells in a micropapillary configuration and not due to true glandular differentiation as also supported by immunohistochemistry. In primary adenocarcinoma of the bladder, there is a greater variability of gland shape and size and of the range of differentiation in contrast to the typically uniform appearance of micropapillary component of urothelial carcinoma.

There are several important reasons for recognizing micropapillary variant of urothelial carcinoma. (1)There is evidence to suggest that this unique configuration of urothelial carcinoma connotes a more aggressive clone of neoplastic cells-(a) these tumors are invariably high grade and usually of high stage and are frequently associated with vascularlymphatic invasion; (b) the amount of micropapillary component is correlated inversely with prognosis, (c) the micropapillary component has a higher DNA index than did conventional urothelial carcinoma (limited cases examined); and (d) metastatic sites of tumors with a micropapillary component are predominantly composed of tumors with this histological pattern. (2) The presence of micropapillary histology in metastatic sites should prompt consideration of the possibility of urothelial carcinoma, especially if the micropapillary configuration is encountered in the peritoneum, abdominal lymph nodes or mesentery of a male patient with an unknown primary or in a female with normal appearing ovaries. (3) The high association of micropapillary carcinoma with muscle-invasive disease should alert the pathologists to its possibility when this histology is encountered. ${ }^{40}$ If the biopsy is superficial and lacks muscularis propria, there should be a suggestion for a re-biopsy and reevaluation for staging. (4) There is recent data that suggest that for micropapillary carcinomas presenting as early stage disease, there is limited response to immunotherapy such that one leading group has advocated for early cystectomy for pTa and pT1 tumors with micropapillary histology. ${ }^{8,45}$ Also patients are likely to progress while on intravesical 
therapy. The prognosis is uniformly unfavorable; the 5 -year and 10-year survival in the largest study was 51 and $24 \%$, respectively. ${ }^{33}$

\section{Lymphoepithelioma-like carcinoma of the urinary bladder}

First reported in 1991, there are $<75$ cases reported in the literature. Tumors with this histology are so termed because of their striking morphological resemblance to the undifferentiated nasopharyngeal carcinoma or lymphoepithelioma. ${ }^{3,46-51}$ They have also been reported at multiple sites, including the prostate, breast, cervix, skin, lung, thymus, stomach and salivary glands. ${ }^{49}$ The neoplastic cells are large and arranged in syncytia, with individual undifferentiated tumor cells with large, pleomorphic vesicular nuclei, prominent nucleoli and numerous mitoses; the cytoplasmic borders are most often indistinct (Figure 8a and b). The sine qua non for this histological pattern of urothelial carcinoma is the presence of a prominent lymphoid infiltrate (both $\mathrm{T}$ and $\mathrm{B}$ cell), although an admixture of other inflammatory cells including plasma cells, histiocytes and eosinophils is not uncommon. The relationship with EBV (by immunohistochemistry and in situ hybridization) has been well explored with no association being documented. ${ }^{47,51}$

The differential diagnosis includes malignant lymphoma, and in limited and crushed biopsies with marked chronic cystitis. Immunohistochemical studies (pan-cytokeratin) are useful in the resolution of these differential diagnoses. High-grade urothelial carcinoma of the usual type with a brisk inflammatory infiltrate should not be termed lymphoepithelioma-like carcinoma simply because of the accompanying inflammatory cells. The syncytial arrangement and typical cytology are essential for the diagnosis of lymphoepithelioma-like carcinoma, which in its purest form may be treated differently than the usual or conventional invasive carcinoma.

Relatively, few series of this subtype of urothelial carcinoma have been reported, and the aggregate data suggest that when these tumors occur in a pure form, they often respond to chemotherapy as the primary treatment modality, providing the potential to salvage bladder function. ${ }^{46,49}$ A majority of reported tumors are muscle-invasive carcinomas (pT2 or higher) and when admixed with conventional urothelial carcinoma, their outcome is similar to that of conventional urothelial carcinoma and depends on the stage of the associated conventional urothelial carcinoma. Some studies have shown that tumors with a predominant lymphoepithelioma-like histology have a more favorable prognosis compared with those with only a focal component of this histology. In a large series, cases treated with cystectomy had a 5 -year actuarial survival rate of $59 \%$ (62\% for pure and $57 \%$ for mixed); in comparison the 5-year recurrence free rate of muscle-invasive bladder cancer treated by cystectomy was similar and in the range of $65-68 \% .^{51}$

\section{Sarcomatoid carcinoma of the urinary bladder}

Although relatively rare, sarcomatoid carcinoma including carcinosarcoma is more common than primary sarcoma of the urinary bladder. ${ }^{52-61}$ More than 100 cases have been reported in the literature and a recent SEER data analysis showed that 301 cases were sarcomatoid carcinomas and carcinosarcomas among 46515 patients $(0.6 \%)$ of bladder cancer. The term carcinosarcoma is used by some authors, and in earlier papers, to designate tumors with overt epithelial histology admixed with sarcomatous histology with heterologous elements. The latest WHO classification, while acknowledging this controversy, endorses the term sarcomatoid carcino-
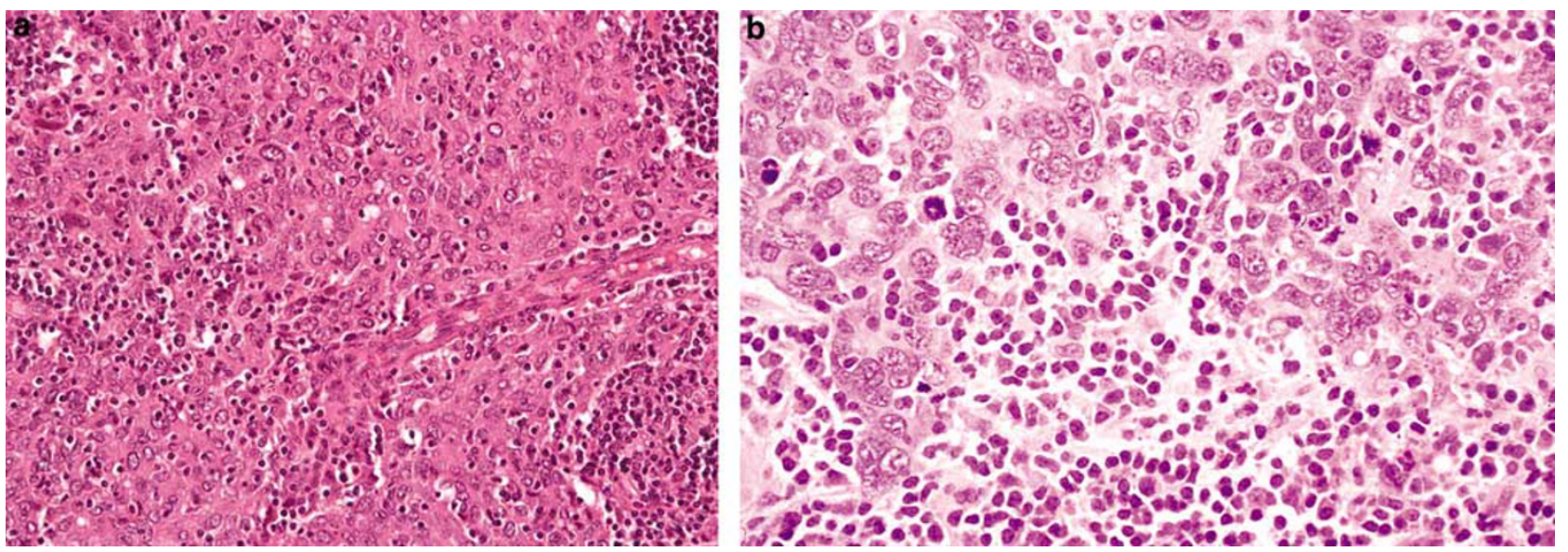

Figure 8 Lymphoepithelioma-like carcinoma of the urinary bladder. (a and b) High power of sheets of cells arranged in syncytia separated by a prominent inflammatory infiltrate. The nuclei are large and vesicular. 
ma, as do others. ${ }^{6,60,62}$ Molecular analyses have shown a common clonal origin for the carcinomatous and sarcomatous components, and the outcome of tumors with and without heterologous elements is largely similar. ${ }^{54,63}$ However, a recent study showed that data reported to the SEER registry and analyzed for outcome strictly on the basis of ICD-O-3 histological code showed that sarcomatoid carcinoma and carcinosarcoma patients did worse than high-grade urothelial carcinoma, and when separated, carcinosarcoma patients did worse than sarcomatoid carcinoma cases. ${ }^{53}$ A potential wellknown shortcoming of analyzing data from large publicly reported databases is that the cases are not centrally reviewed by a group of dedicated pathologists, and differing criteria and nomenclature may be used by pathologists. It is likely that as many leading centers, classification schemes and papers have adopted and endorsed a unifying approach for terminology, this has likely influenced and compounded analyses of data evaluated without ascertaining if uniform criteria are used and without a histological re-review of the study. ${ }^{60,62}$

The sarcomatoid areas (obvious sarcomatoid overgrowth) may merge with foci of urothelial carcinoma (Figure 9a), squamous cell carcinoma, adenocarcinoma or small-cell carcinoma, and most commonly resemble a high-grade sarcoma, not otherwise specified, or have a malignant fibrous histiocytoma histology. Heterologous differentiation may be present but has no definite prognostic significance (Figure 9b). In decreasing order of frequency, areas of osteosarcoma, chondrosarcoma, rhabdomyosarcoma, liposarcoma, angiosarcoma or a mixture of sarcoma histologies may be seen. In the absence of an obvious invasive carcinoma (urothelial, glandular, small cell, and so on), in a primarily malignant spindle cell tumor of the bladder, history of prior urothelial neoplasia, coexistence of in situ disease such as urothelial carcinoma in situ or strong and relatively diffuse cytokeratin immunoreactivity is helpful in making the diagnosis of sarcomatoid carcinoma over a primary sarcoma. Earlier treatment with radiation therapy and intravesical cyclophosphamide chemotherapy has been associated with sarcomatoid carcinoma, as also with external beam radiation for prostate cancer. ${ }^{64}$

The differential diagnosis includes benign or locally aggressive conditions, including pseudosarcomatous myofibroblastic proliferations (postoperative spindle cell nodules and pseudotumors (inflammatory myofibroblastic tumors)) of the bladder, urothelial carcinoma with chondroid or osseous metaplasia (ie the absence of osteoid or atypical cartilage) and primary sarcomas, chiefly leiomyosarcoma. ${ }^{65,66}$ Pseudosarcomatous myofibroblastic proliferations may form large mass lesions that protrude in the bladder lumen as a polypoid tumor and/or widely involve the bladder wall including the muscularis propria. High cellularity, frequent mitoses (not atypical) and necrosis along with an infiltrative growth compound the distinction with sarcomatoid carcinoma. The lesion frequently has a myxoid background with granulation-tissue-type vascularity, extravasated red cells and an inflammatory infiltrate. A zonal pattern of distribution, that is, more myxoid and hypocellular regions toward the surface and greater cellularity with a fibrous background toward the base, a 'nodular fasciitis'type appearance of the lesion, the absence of an epithelial component and the absence of nuclear atypia (hyperchromasia, chromatin abnormalities and anaplasia) are key in distinction from a malignant process. A subgroup of sarcomatoid carcinomas may have a more prominent myxoid background and may add to the marked diagnostic overlap and to the difficulty in discrimination between the two entities. ${ }^{55}$ Also, it is the author's anecdotal
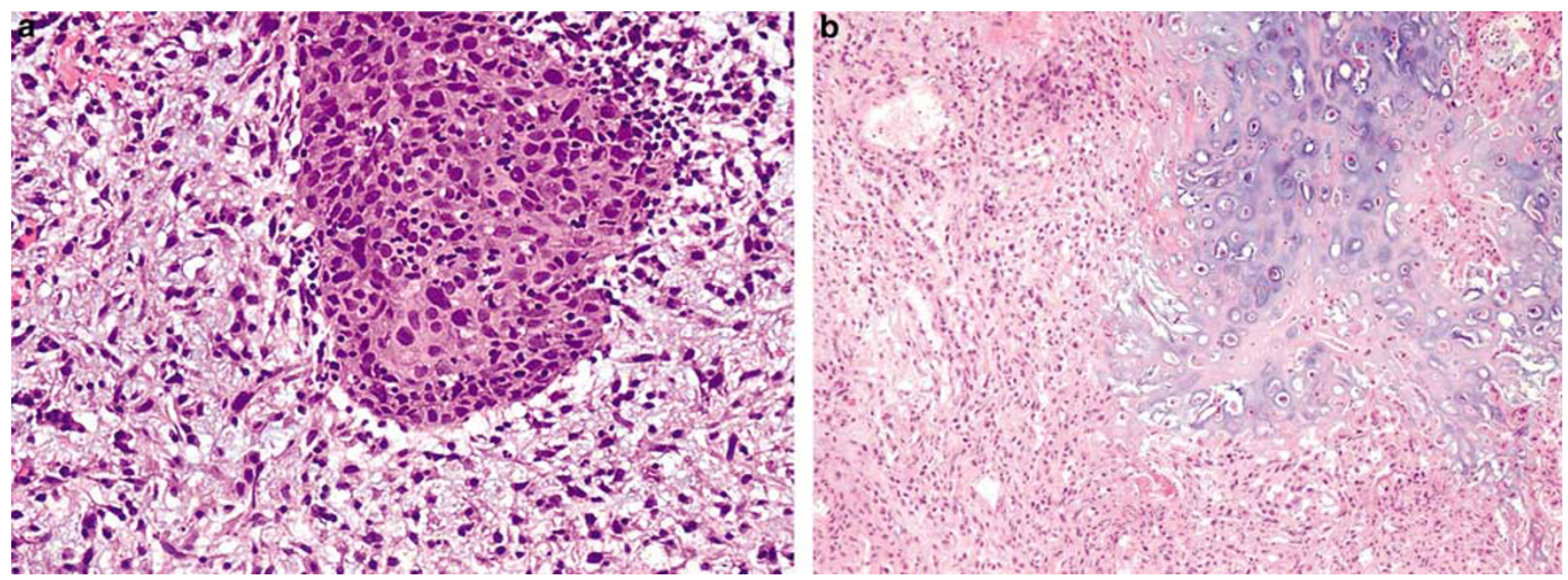

Figure 9 Sarcomatoid carcinoma of the urinary bladder. (a) Urothelial carcinoma and high-grade spindle cell morphology of sarcomatoid component. (b) Heterologous cartilaginous differentiation. 
experience, which has to some degree also been commented upon in the literature, that leiomyosarcomas of the urinary bladder also have a more prominent myxoid appearance.

Immunohistochemistry, similar to morphology, has marked overlap in staining characteristics between pseudosarcomatous myofibroblastic proliferations, sarcomatoid carcinoma and leiomyosarcomas, although we have recently found that use of a judicious panel (pan-cytokeratin, smooth muscle actin, desmin, Alk-1, p63, CK5/6 and/or high-molecular-weight cytokeratin) interpreted strictly within the morphological context may be of some value (Table 4). ${ }^{66}$ Pseudosarcomatous myofibroblastic proliferations are usually positive for pan keratin, smooth muscle actin, desmin and alk-1. Sarcomatoid carcinomas may also be positive for pan-cytokeratin, smooth muscle actin and rarely with desmin, but may be distinguished by their positivity for p63, CK5/6 and high-molecular-weight cytokeratin (in $10-40 \%$ of cases). Leiomyosarcomas are positive for actin, desmin (usually extensively) and occasionally for pan-cytokeratin (usually weak or focal). They are negative for p63, CK5/6, highmolecular-weight cytokeratin and Alk- $1 .^{24}$ The differential immunostaining and the extent of staining of individual markers between these three differential diagnostic considerations are important in the ultimate weight of support immunohistochemistry provides in this difficult area.

There are no standardized clinical management paradigms for sarcomatoid carcinoma, and adjuvant therapy tends to vary from institution to institution and may be different from the therapy for a primary sarcoma such as a leiomyosarcoma. Limited experience has shown down staging (pT0 at cystectomy) for almost half the patients in one center's experience. ${ }^{8}$ Almost all sarcomatoid carcinomas present at a high stage, frequently exhibit nodal and/or distant metastasis and have a very poor prognosis. An estimated $70 \%$ of patients die within 2 years of diagnosis.,52-61 Compared with patients with urothelial carcinomas alone, these patients are at a greater risk for death even after adjusting for the stage at presentation.

\section{Small-cell carcinoma}

Approximately 400 cases including several large series have been reported in the literature. The mean age of presentation is 67.8 years and there is a striking male predisposition-5:1. ${ }^{67-78}$ More than $90 \%$ of patients present with hematuria; rare cases present with paraneoplastic syndromes including hypercalcemia, Cushing's syndrome and sensory neuropathy.

Morphologically, this tumor is identical to the undifferentiated small-cell carcinoma of the lung, but is more frequently admixed, in approximately $40-50 \%$ of the cases, with an epithelial component of urothelial carcinoma (Figure 10a), including carcinoma in situ, squamous cell carcinoma or adenocarcinoma, and rarely even a sarcomatoid component. Molecular genetic evidence suggests a common clonal evidence for small-cell carcinoma and coexistent urotheilal carcinoma. The tumor usually has a patternless pattern of diffuse growth, although occasionally and focally some nesting may be present. The cells have scant cytoplasm and consequently show nuclear crowding and molding (Figure 10b). Nucleoli are inconspicuous and the chromatin is finely stippled. Geographic necrosis, frequent mitoses, crush artifact, and Azzopardi effect are indicative of its high proliferation rate. In the authors' personal experience, some small-cell carcinomas of the urinary bladder do not have features typically seen in small-cell carcinomas of the lung. In cases that have the overall cytoarchitectural features and adequate immunohistochemical support, I have taken the liberty to continue to designate tumors without the classic morphology as small-cell carcinoma of the bladder.

Tumors are positive for chromogranin A and synaptophysin (greater than $60 \%$ of cases) and frequently show a dot-like positivity for pan-cytokeratin. TTF-1 may be positive in almost $40 \%$ of the cases. ${ }^{68}$ Other reported markers include p53 (75\%), c-kit $(27 \%)$ and EGFR $(27 \%)$; prognostic or therapeutic significance of these markers is unknown. ${ }^{67,79}$ Comparative genomic hybridization studies show frequent genomic alterations including deletions

Table 4 Spindle cell proliferations of the urinary bladder in adults: reported immunoprofiles

\begin{tabular}{lccc}
\hline & Bladder PMP & Sarcomatoid carcinoma & Leiomyosarcoma \\
\hline Actin & $48-100 \%$ & $15-80 \%$ & $43-100 \%$ \\
Desmin & $27-80 \%$ & $0-40 \%$ & $0-60 \%$ \\
h-caldesmon & $0-66 \%$ & $\mathrm{~N} / \mathrm{D} \%$ & $100 \%$ \\
CKAE1/3 & $36-94 \%$ & $63-100 \%$ & $0-58 \%$ \\
CK 5/6 & $0 \%$ & $27-65 \%$ & $0 \%$ \\
HMCK & $0 \%$ & $0-25 \%$ & $0 \%$ \\
P63 & $0 \%$ & $36-70 \%$ & $23 \%$ \\
EMA & $0-50 \%$ & $50-100 \%$ & $0-12 \%$ \\
ALK-1 & $20-89 \%$ & $0 \%$ & $0-10 \%$ \\
\hline
\end{tabular}

PMP, pseudosarcomatous myofibroblastic proliferation; HMCK, high-molecular-weight cytokeratin. 

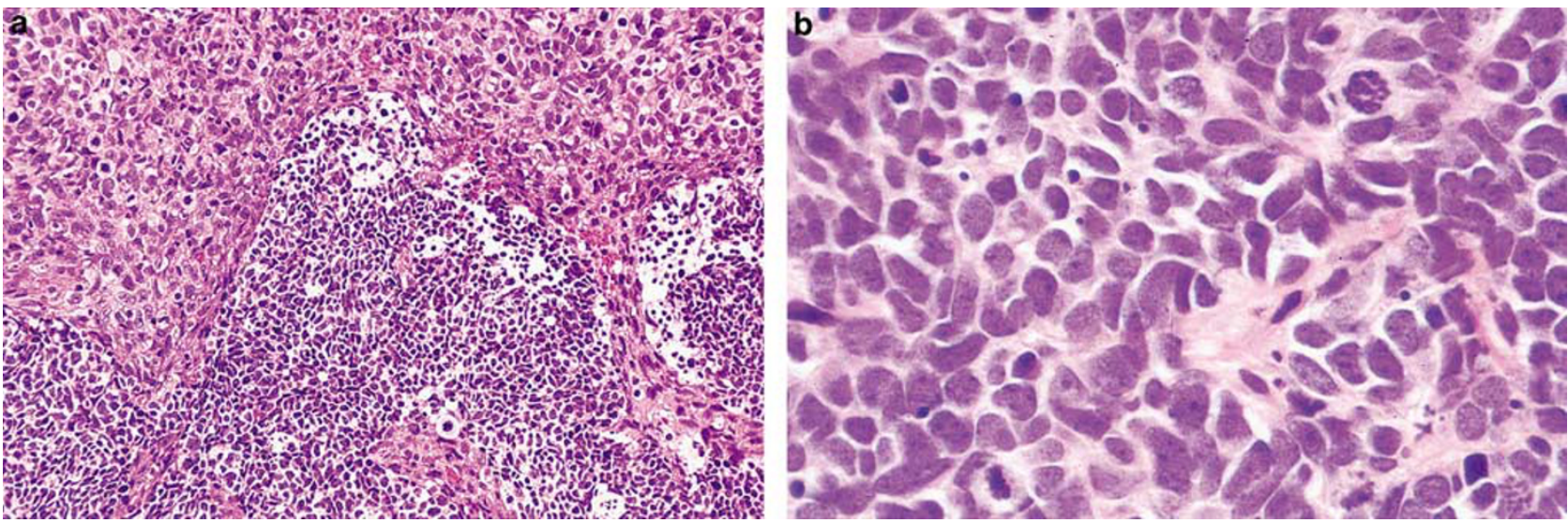

Figure 10 Small-cell carcinoma of the urinary bladder. (a) High-grade conventional urothelial carcinoma juxtaposed with small-cell carcinoma histology. (b) Typical cytological features of small cell carcinoma component.

of $10 q, 4 q, 5 q$ and $13 q$, and gain of $8 p, 5 p, 6 p$ and $13 \mathrm{q} .{ }^{80}$ Methylation studies show similar rates in pure small-cell carcinoma and in small-cell carcinoma concurrent with urothelial carcinoma. ${ }^{81}$

Small-cell carcinoma may be mistaken for malignant lymphoma, poorly differentiated urothelial carcinoma with scant cytoplasm and even inflammation in a crushed, cauterized, superficial or scant specimen. Metastasis from lung or extension from adjacent viscera must be ruled out by clinicopathological correlation as immunohistochemistry offers limited assistance. TTF-1 may be expressed in small-cell carcinomas of any anatomic site, and does not indicate a lung origin and PSA is usually negative in prostatic small-cell carcinomas. ${ }^{68,72}$ If the tumor is not felt to be a typical primary bladder neoplasm at presentation, attention to the morphology of the accompanying epithelial component such as prostatic or urothelial histology, if present, would be useful to determine the primary site. Another significant diagnostic pitfall is alveolar rhabdomyosarcoma, which may rarely involve the bladder and has a predilection to occur in adults. It may occur either in a pure form or as a component of heterologous differentiation in a sarcomatoid carcinoma. These tumors have significant overlap with small-cell carcinoma, as the classic 'alveolar' morphology may not be appreciated and the tumor may present with an almost exclusive round-cell primitive appearance. The tumors are positive for desmin, myogenin and Myo D1 and negative for keratin. The morphologic overlap is compounded by synaptophysin immunoreactivity (hitherto unexplained) in alveolar rhabdomyosarcomas. ${ }^{82}$

The vast majority of patients (94\%) with smallcell carcinoma of the bladder present with muscleinvasive disease and $\sim 67 \%$ patients develop systemic metastases during the disease course. Metastastic sites include lymph nodes, liver, bone, lung and brain. An important reason for the accurate recognition of a small-cell carcinoma component is that it is recognized as a systemic disease and apparently has response to newer chemotherapy protocols (cisplatin- and etoposide-based therapy), which, in combination with surgical resection, have shown encouraging results including reports of longterm survivors. It is difficult to compare outcome between different series, as different therapeutic strategies, including surgery alone, neoadjuvant and adjuvant chemotherapy, radiation therapy, and so on, have been variably employed. ${ }^{69,83}$ The mean survival is 6-34.9 months and the reported 5-year survival rate ranges from 8 to $40 \%$; patients presenting with organ-confined disease have a slightly favorable survival. ${ }^{67-78,83}$ In another large single institution experience, the 5-year disease-specific survival of patients undergoing cystectomy alone was 36 and $78 \%$ in those receiving chemotherapy, underscoring the importance of accurate histopathological classification of small-cell carcinoma. ${ }^{84}$

\section{Large-cell neuroendocrine carcinoma}

The range of neuroendocrine tumors in the bladder includes carcinoid tumor, small-cell carcinoma, large-cell neuroendocrine carcinoma and mixed patterns. ${ }^{85}$ Less than 10 convincing cases of pure carcinoid tumor of the urinary bladder and $<10$ cases of primary large-cell neuroendocrine carcinoma of the urinary bladder have been reported using criteria used for their better-known pulmonary counterparts. ${ }^{86-91}$ In contrast to small-cell carcinoma, large-cell neuroendocrine carcinomas have a more discernable architecture (nests, trabeculae, organoid and palisaded) and have prominent nucleoli. Large-cell neuroendocrine carcinomas may be pure (rare) or admixed with components of urothelial, glandular, squamous or small-cell carcinoma. Reported outcome data on primary pure carcinoid tumors are extremely limited and not adequate to make any reliable inference on the prognosis. The outcome of large-cell neuroendocrine carcinoma appears to be similar to small-cell 
carcinoma with most reported cases having a fatal outcome.

\section{Urothelial carcinoma with trophoblastic differentiation}

More than 30 cases of urothelial carcinoma with areas of trophoblastic differentiation have been reported and a small subset has had symptoms related to excess human chorionic gonadotropin production including gynecomastia. ${ }^{92-96}$ Although some of the early reports have described tumors that apparently were composed solely of tissue resembling choriocarcinoma, most tumors reported in the last three decades or so have been composed of a mixture of urothelial carcinoma with trophoblastic elements. A single case of micropapillary carcinoma with trophoblastic elements has been reported. ${ }^{43}$

For purposes of reviewing clinical significance, we divide this group of neoplasms into three categories: (1) urothelial carcinoma with scattered syncytiotrophoblasts, (2) urothelial carcinoma with choriocarcinomatous differentiation (Figure 11a and b) or pure choriocarcinoma, and (3) urothelial carcinoma with immunohistochemical expression of $\beta$-HCG, but no recognizable trophoblasts. Thus, trophoblastic differentiation in urothelial carcinoma spans a spectrum from immunohistochemical expression for human chorionic gonadotropin in an otherwise typical invasive urothelial carcinoma to the presence of syncytiotrophoblasts, to the presence of focal areas resembling choriocarcinoma, to the rare predominant or pure choriocarcinoma, which is recognized as a variant of urothelial carcinoma rather than a neoplasm of germ cell origin. One recently reported case, however, was associated with an isochromosome $12 \mathrm{p}$, a specific genetic marker found in germ cell tumors of any histological type. ${ }^{97}$

Immunohistochemistry can often detect human chorionic gonadotropin in typical urothelial carcinoma and some variants, including carcinoma in situ and plasmacytoid variant. ${ }^{98}$ This is more common in high-grade carcinoma, approaching 33\% of cases. Areas with positive staining may be juxtaposed to identical areas without demonstrable staining. The presence of syncytiotrophoblasts has been associated with a poor prognosis; in most cases, <12 months have elapsed between the presentation and death. For this reason, the presence of elements with trophoblastic morphology and some estimate as to their quantity should be reported. Also, elevated urine or serum $\beta$-HCG levels in these patients offer a marker for response to therapy. ${ }^{95}$ There has been no study comparing tumors of similar grade and stage with and without admixed syncytiotrophoblasts to definitively answer this question. It does appear that choriocarcinomatous differentiation has a higher risk of metastatic disease and tumor related death. Owing to of its rarity, the utility of germ cell therapy for vesical choriocarcinoma has not been fully addressed; initial cases reported a poor response, but there are reports of good clinical responses to germ cell therapy in rare patients with pure choriocarcinomas. ${ }^{96}$ Whether or not pure choricarcinoma of the bladder represents a tumor with better chemosensitivity is unknown. The possibility of a metastatic choriocarcinoma should always be excluded clinically before the diagnosis of a primary vesical choriocarcinoma is accepted, involution of testicular tumors is well known and small, residual testicular scars may be the only clinical sign of primary disease.

\section{Urothelial carcinoma with unusual cytoplasmic features}

\section{Plasmacytoid Urothelial Carcinoma}

In the past few years, urothelial carcinomas with a striking resemblance to plasma cells have been described..$^{98-109}$ The first case was reported by Sahin et al in 1991, in which the patient presented with multiple lytic bone metastasis compounding the diagnostic dilemma. Since then $\sim 75$ cases have
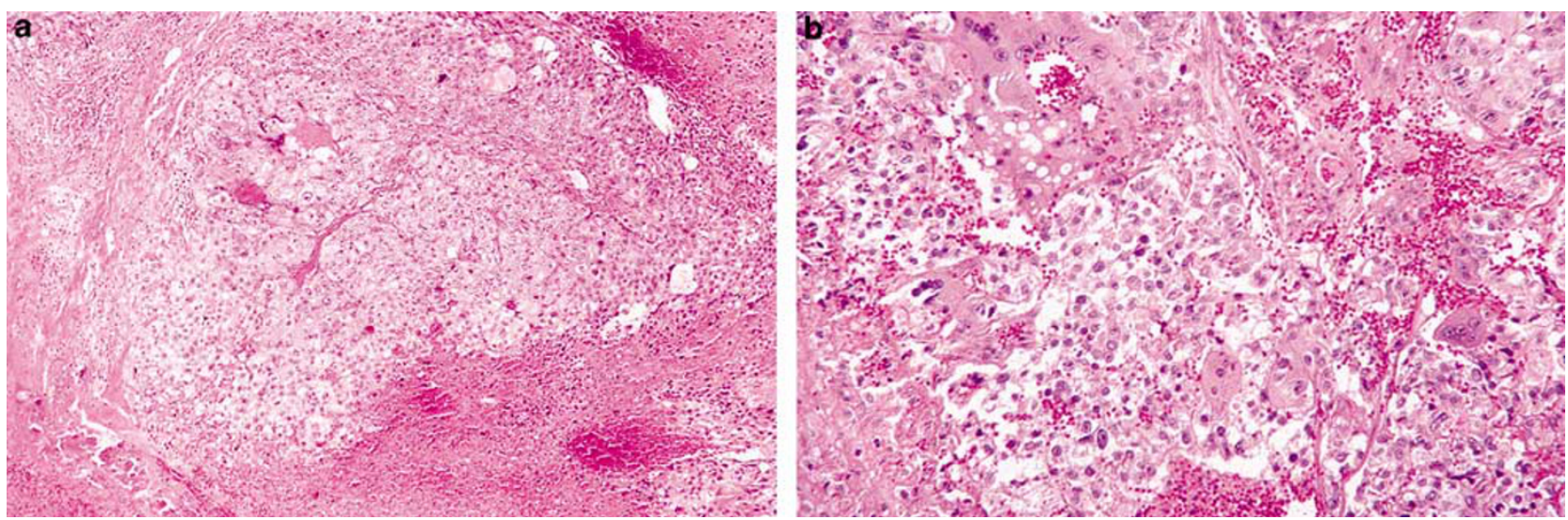

Figure 11 Urothelial carcinoma with trophoblastic differentiation. (a and b) Choriocarcinoma component with biphasic histology including syncytiotrophoblastic giant cells. (Adopted with permission from Dr Jae Y. Ro, Houston, TX, USA.) 

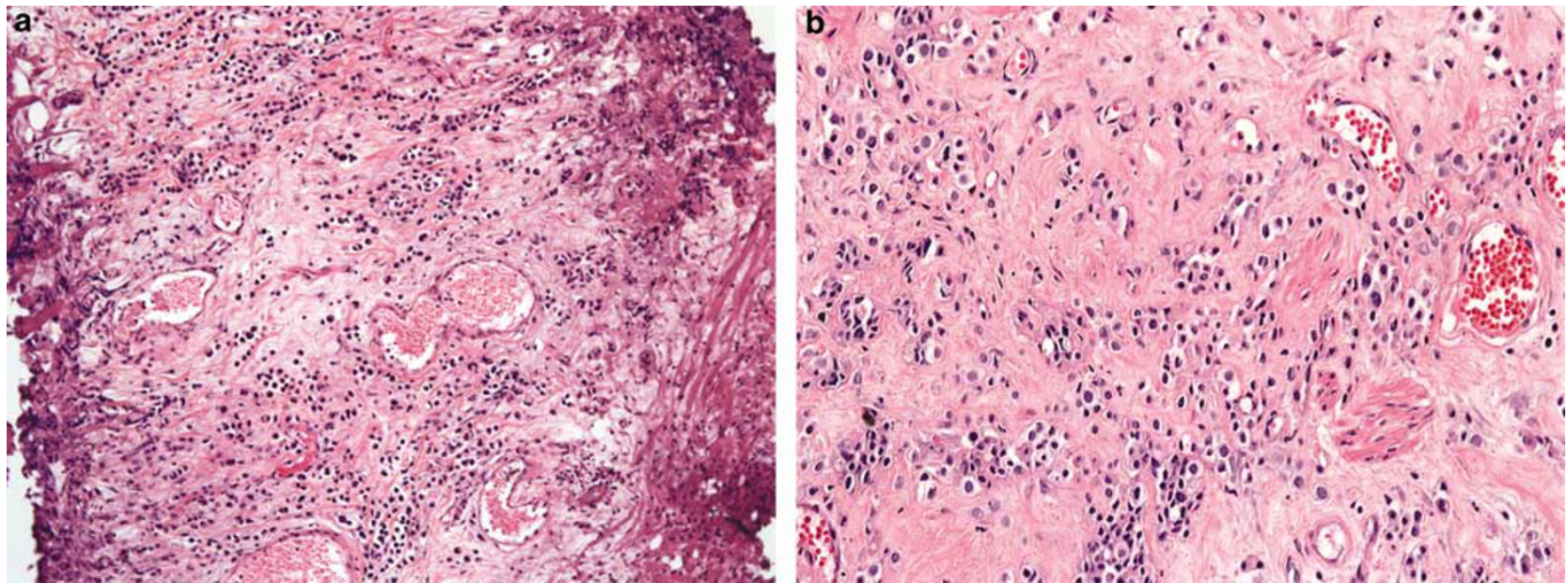

Figure 12 Plasmacytoid urothelial carcinoma. (a) Low-power view of neoplastic infiltrate that may mimic an inflammatory process. (b) Carcinoma cells with plasmacytoid features.

been published with a recent large series of 17 cases. ${ }^{98-109}$ A series of 10 cases mimicking lobular carcinoma of the breast, the so-called discohesive variant, shares many features with the plasmacytoid variant, although the most distinctive feature of cases in this series was the arrangement of tumor cells in a single cell discohesive Indian file pattern. ${ }^{110}$

The tumors are poorly differentiated to undifferentiated, usually having a coexisting typical highgrade urothelial carcinoma or a sarcomatoid carcinoma histology. The neoplastic cells are usually discohesive and set in a loose, myxoid stroma (Figure 12a and b). A plasmacytoid histology may be seen in a variety of bladder neoplasms, including malignant lymphomas, plasmacytomas and malignant melanoma, metastatic carcinoma including lobular and gastric adenocarcinoma, paraganglioma, rhabdomyosarcoma and urothelial carcinoma. The correct diagnosis may not always be difficult if adequate tissue exhibiting more typical patterns diagnostic of a particular neoplasm is available for histological examination. Small biopsies occasionally show only the plasmacytoid pattern and may closely mimic a plasmacytoma or lymphoma. Immunohistochemistry may be required in this setting, and demonstration of cytokeratin reactivity confirms the diagnosis of carcinoma. A broad panel including cytokeratin, leukocyte common antigen and/or T- and B-cell markers and S-100 protein may be necessary if the initial differential diagnosis is wide. In the differential with metastatic carcinoma, plasmacytoid carcinomas are positive for cytokeratin 7 and 20 and for uroplakin3; they may occasionally to commonly express CD138, so this marker should not be used in isolation as evidence of a plasma cell neoplasm. ${ }^{103,104}$

The prognosis of tumors with this morphology is uniformly poor, with most patients having advanced stage at presentation and metastastic disease progression. Owing to the limited number of cases

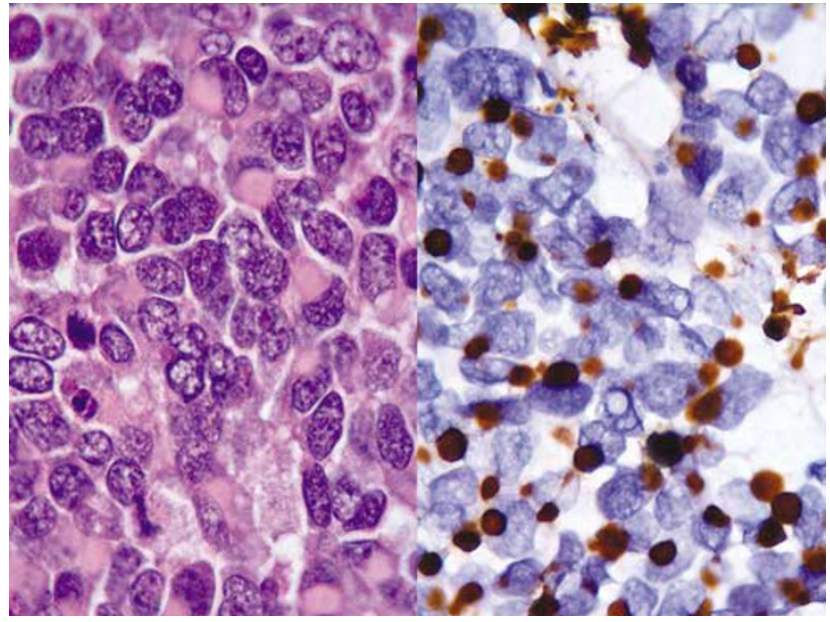

Figure 13 Urothelial carcinoma with rhabdoid features. Left: undifferentiated carcinoma with rhabdoid cells. Right: cytokeratin stain with perinuclear inclusions (Adopted with permission from Dr Anil Parwani, Pittsburgh, PA, USA).

reported, it is difficult to infer if the poor prognosis is related to this particular histological pattern or because of the frequently present concurrent highgrade and high-stage urothelial carcinoma.

\section{Urothelial Carcinoma with Rhabdoid Features}

Urothelial carcinomas may also rarely have focal areas showing rhabdoid features: a population of large, relatively discohesive cells with distinct cell borders, large vesicular nuclei, prominent nucleoli and eosinophilic cytoplasmic inclusions (Figure 13). Less than 10 cases have been reported in adults. ${ }^{111,112}$ Most cases have features of conventional urothelial carcinoma at least focally; concurrent carcinoma in situ, small-cell and sarcomatoid histology have been reported.

The differential diagnosis includes more entities when the tumor has a homogeneous rhabdoid 
phenotype. The main distinction is from a true malignant extrarenal rhabdoid tumor. Although there are two case reports of 'true' malignant rhabdoid tumors of the bladder in young patients, their existence is controversial. Given that malignant rhabdoid tumors have a characteristic mutation or deletion of the INI1 gene at chromosome 22q11, we suggest that molecular confirmation is mandatory for the diagnosis of primary pure malignant rhabdoid tumor of the bladder. Immunohistochemical loss of nuclear INI1 expression has also been reported as an adjunctive test to confirm the diagnosis of malignant extra-renal rhabdoid tumors. ${ }^{113}$ From a practical standpoint, tumors with a rhabdoid morphology in adults are almost always poorly differentiated carcinomas. The prognosis of these tumors is poor and characterized by an aggressive clinical course.

\section{Urothelial Carcinoma with Clear Cell Features (Glycogen-Rich)}

Reports have described urothelial carcinomas with glycogen-rich, clear cytoplasm. ${ }^{114-118}$ These carcinomas are typically high grade, so the differential diagnosis includes clear cell adenocarcinoma, metastatic renal cell carcinomaor prostatic carcinoma. Clear cell adenocarcinomas of the bladder more frequently occur in women and typically have a combination of morphological patterns within the same tumor including, solid, papillary or tubulocystic architectural arrangement; the papillae are lined by a single epithelial layer with a hyalinized core. The cytoplasm may be eosinophilic or clear and the cells may have a hob nail appearance. In contrast, poorly differentiated urothelial carcinomas with clear cell features have a more sheet-like growth pattern and often have more characteristic appearing areas, at least focally, of urothelial carcinoma with conventional morphology (Figure 14). Clear cell carcinomas may be positive for cytokeratin 7 and CA 125, and occasionally for cytokeratin 20. Metastatic renal cell carcinoma can usually be excluded on the basis of clinical grounds (the presence of renal mass). In the one reported series of seven cases of renal cell carcinoma metastatic to bladder, all patients had metastasis in multiple organs; no patient had isolated bladder metastasis. ${ }^{19}$ It is conceivable, although that a vesical involvement may be the initial manifestation of renal cell carcinoma. Morphologically, the presence of a well-developed alveolar or nested pattern with intervening interconnecting septa containing a lattice arrangement of capillaries and admixed mature lymphocytes should greatly raise suspicion of a renal primary. Co-expression of cytokeratin and vimentin, positivity for RCC antigen and PAX-2, and negative reaction for cytokeratin 7 and 20 provide immunohistochemical support for the diagnosis of renal cell carcinoma. ${ }^{120}$ Prostatic carcino-

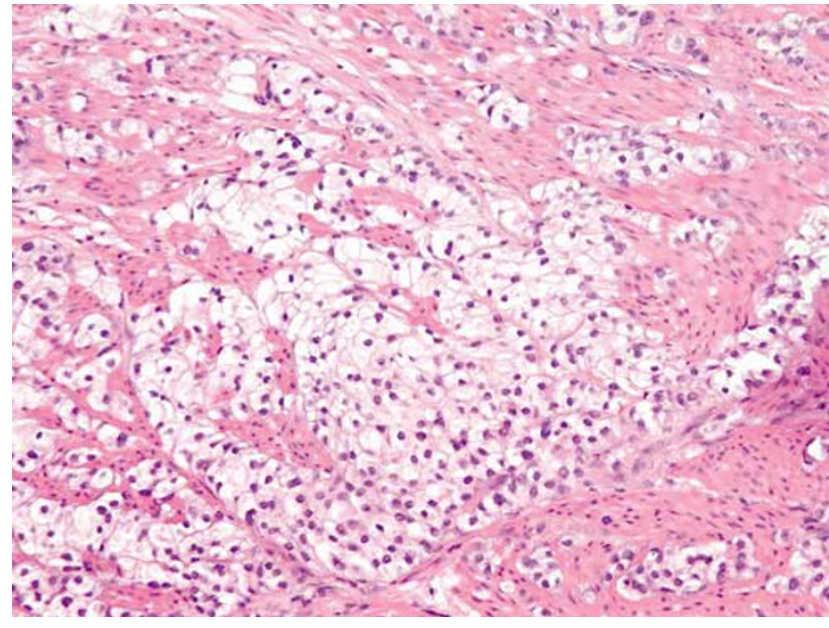

Figure 14 Urothelial carcinoma with clear cell features. Invasive carcinoma has cells with abundant clear cytoplasm. Other areas of the neoplasm had more typical morphology of urothelial carcinoma.

mas typically involve the muscularis propria and may spare the lamina propria and the lining mucosa, as it directly invades the bladder wall from the prostate. Even the high-grade and high-stage prostatic adenocarcinomas most typically show more homogenous nuclear features with prominent nucleoli. Appreciation of a multitude of patterns, including cribriform, small acinar and solid, and the cytological tinctorial appearances, such as clear, eosinophilic, and foamy pattern, may be useful. Pleomorphism and frequent mitoses are unusual for prostate carcinoma. Strong, diffuse immunoreactivity with PSA and/or PSAP would support a prostatic carcinoma. Urothelial carcinomas are positive for cytokeratins 7 and 20 and for p63, thrombomodulin and high-molecular-weight cytokeratin; markers usually negative in prostate carcinomas. ${ }^{24,44,121}$ Recently, additional prostate-specific markers, including P501S, and prostate-specific membrane antigens have made this differential diagnosis be more readily resolved by immunohistochemistry. ${ }^{122}$

\section{Lipoid-Rich Variant of Urothelial Carcinoma}

The most recent WHO classification recognizes that rare urothelial carcinomas may have large carcinoma cells with optically clear empty multivacuolated cells resembling lipoblasts. ${ }^{6}$ The lipid-rich cellular areas comprise from $<10$ to up to $50 \%$ of the tumor and, when prominent, raise the possibility of a signet ring component (glandular differentiation) or of heterologous liposarcomatous elements of a sarcomatoid carcinoma. Less than 10 cases are reported, in which the presence of lipid has not convincingly been proven by histochemistry and hence the term lipoid variant. ${ }^{123}$ The cells are S-100 protein-negative. The background urothelial carcinoma is invariably high grade and invasive (Figure 15a and b). The 

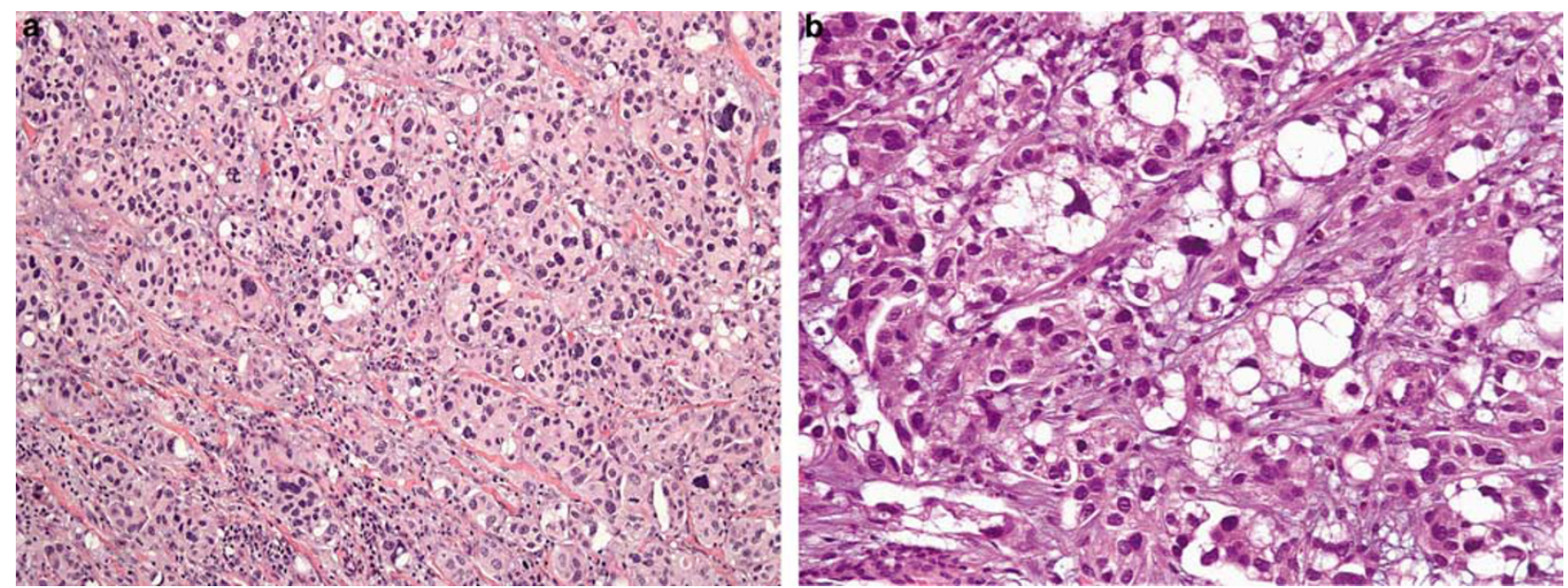

Figure 15 Lipoid-rich variant of urothelial carcinoma. (a) Urothelial carcinoma with cells resembling lipoblasts. (b) High power.

absence of intracellular mucin by special stains may aid in the distinction from a signet ring cell component, but is rarely necessary when one puts this unusual observation in the context of the morphology of the entire invasive carcinoma. The demonstration of cytokeratin reactivity should resolve the diagnosis of carcinoma in the most difficult case. There is no known prognostic significance of this histological variant of bladder cancer.

\section{Urothelial carcinoma with unusual stromal reactions}

\section{Pseudosarcomatous Stroma}

Urothelial carcinomas may have a pseudosarcomatous stromal response in the primary or metastatic neoplasm. ${ }^{65,124,125}$ In these cases, the stroma, adjacent to the epithelial component, contains atypical mesenchymal cells that are similar to those seen in giant cell cystitis. The chief reason for the awareness of this peculiar stromal response is that it should not be misinterpreted as the biphasic component of a sarcomatoid carcinoma. The superficially very atypical appearing spindle cells often have abundant eosinophilic cytoplasm and pleomorphic hyperchromatic nuclei that have a degenerate or 'symplastic' appearance. The spindle cell component lacks mitotic activity or an expansile growth, and there is a lack of transition between the spindle cells and the carcinoma cells.

\section{Osseous or Cartilaginous Metaplasia}

The stroma of urothelial carcinomas or their metastases may rarely undergo osseous or cartilaginous metaplasia. This feature should not be mistaken for heterologous differentiation in a sarcomatoid carcinoma (carcinosarcoma). The bone or cartilage appears mature and lacks cytologic atypia. ${ }^{1,126}$
Table 5 Urothelial carcinoma with giant cells

1. Giant cell carcinoma

2. Sarcomatoid carcinoma with anaplastic spindle cell giant cells

3. High-grade urothelial carcinoma with syncytiotrophoblasts and/or choriocarcinomatous elements

4. Urothelial carcinoma with osteoclast-like stromal response

5. Osteoclast-rich undifferentiated carcinoma

6. Urothelial carcinoma with treatment associated giant cells (post-BCG or post-transurethral resection)

\section{Osteoclast-Type Giant Cells}

Giant cells resembling osteoclasts occasionally are present in the stroma of bladder carcinoma. Rare cases of tumors with predominant osteoclast-type giant cell histology have been reported (see below), and tumors with focal osteoclast-like giant cells should not be misclassified as these giant cell-rich bladder carcinomas (Table 5). ${ }^{127-130}$

\section{Osteoclast-rich undifferentiated carcinoma of the urinary bladder}

'Giant cell tumors' or 'osteoclastoma-like giant cell tumors' of the pancreas, gall bladder, liver, breast, salivary gland, thyroid, skin, lung, intestines, larynx and female genital tract have been reported. Less than 20 cases of a similar spectrum have been reported in the bladder, most as case reports, with one series of 6 cases. ${ }^{127-132}$ The tumors are composed of mononuclear cells (frequently positive for epithelial markers), osteoclast-like giant cells (CD68-, CD51-, CD54-positive) (Figure 16a and b) and recognizable usual urothelial neoplasia (carcinoma in situ, papillary or invasive carcinoma) in varying proportions. ${ }^{131}$ Some areas may be entirely composed of histology similar to giant cell tumors of bone, whereas other areas may show single cells or aggregates of mononuclear cells with a spectrum of 

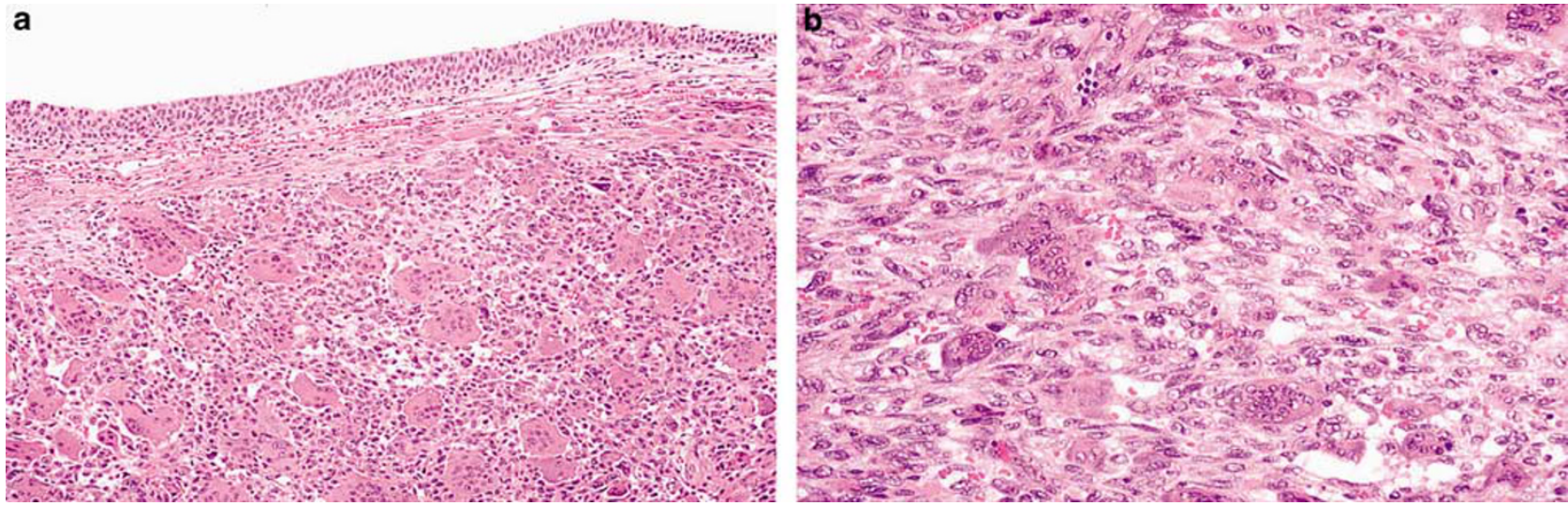

Figure 16 Osteoclast-rich undifferentiated carcinoma of the urinary bladder. (a) Neoplasm composed of numerous osteoclast-like giant cells. (b) Atypical mononuclear and spindled cells are the undifferentiated neoplastic component.

atypia, including marked pleomorphism, which are distinct from the nuclei of the osteoclast-like giant cells. These mononuclear cells may stain for pancytokeratin, epithelial membrane antigen, CAM 5.2 and cytokeratin 7; and rarely for S-100 protein, actin, desmin and p53. ${ }^{131}$ Although these tumors have several histological features of their skeletal counterparts including areas with blood-filled cysts mimicking aneurysmal bone cyst, we believe them to be undifferentiated carcinomas that are rich in osteoclasts because of the cytokeratin positivity, concurrent presence of high-grade urothelial neoplasia, matched p53 positivity in mononuclear cells and urothelial tumor cells, and the poor prognosis of tumors with this histology. In the series of six cases, four of five patients with follow-up died of disease, three with documented metastasis. ${ }^{131}$ A large majority of patients reported in case reports that have adequate follow-up have also had documented metastatic disease or death. ${ }^{129,131,132}$

\section{Giant cell carcinoma}

Very rarely undifferentiated carcinomas of the bladder may be composed predominantly or purely of poorly differentiated large, loosely cohesive pleomorphic, bizarre and anaplastic cells with abundant eosinophilic or amphophilic cytoplasm (Figure 17). The tumor cells often contain multiple nucleoli and are similar to giant cell carcinomas seen in the lung and in other parts of the body. Multiple nuclei and/or macronucleoli are common. ${ }^{2,4}$ This pattern likely represents a form of poorly differentiated/undifferentiated urothelial carcinoma and many authors prefer the term 'undifferentiated carcinoma' for these tumors. There is no known difference in prognosis or response to therapy from other forms of high-grade urothelial carcinoma, but no studies have addressed this issue to date. The prognosis is likely to be poor based on experience in similar tumors occurring at other sites. The high degree of nuclear anaplasia helps

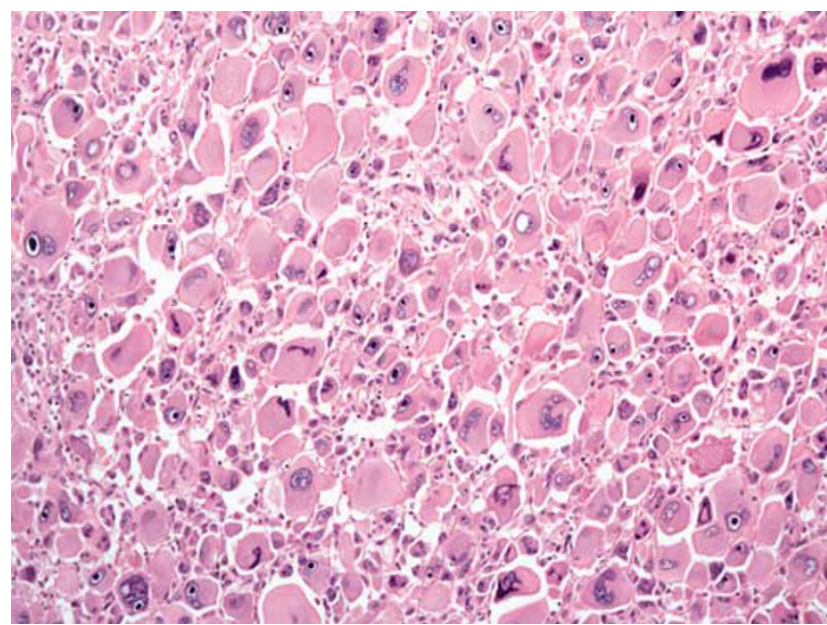

Figure 17 Giant cell carcinoma of the urinary bladder.

differentiate giant cell carcinoma from the urothelial carcinoma with osteoclast-type giant cells or syncytiotrophoblasts. Other diagnostic issues include the differential diagnosis from other poorly differentiated malignant neoplasms including lymphoma and melanoma. Immunostains for epithelial, lymphoid and melanocytic markers should help resolve most cases.

\section{Summary of histological variants of urothelial carcinoma}

Table 6 provides a comprehensive summary of the diagnostic, prognostic and therapeutic significance of the histological variants of bladder cancer; and Table 7 summarizes the immunohistochemical markers associated with urothelial differentiation. From the above wide histological spectrum of invasive urothelial carcinoma, it is amply apparent that urothelial neoplasia has a pronounced ability for divergent differentiation. It is important that surgical pathologists be aware of this potential for multidirectional differentiation, as the correct 
Table 6 Summary of histologic features of variants of urothelial carcinoma and their clinical or pathologic significance

\begin{tabular}{|c|c|}
\hline Variant & Differential diagnosis \\
\hline $\begin{array}{l}\text { Urothelial carcinoma with } \\
\text { squamous differentiation }\end{array}$ & Pure squamous carcinoma \\
\hline $\begin{array}{l}\text { Urothelial carcinoma with } \\
\text { glandular differentiation }\end{array}$ & $\begin{array}{l}\text { Pure primary adenocarcinom } \\
\text { Metastatic adenocarcinoma }\end{array}$ \\
\hline Nested variant & $\begin{array}{l}\text { Von Brunn's nests } \\
\text { Paraganglioma } \\
\text { Nephrogenic adenoma } \\
\text { Metastatic prostate cancer } \\
\text { Carcinoid tumor }\end{array}$ \\
\hline Tubular variant & $\begin{array}{l}\text { Cystitis cystica } \\
\text { Cystitis cystica glandularis } \\
\text { Nephrogenic adenoma } \\
\text { Primary adenocarcinoma } \\
\text { Metastatic adenocarcinoma }\end{array}$ \\
\hline Microcystic pattern & $\begin{array}{l}\text { Cystitis cystica glandularis } \\
\text { Nephrogenic adenoma } \\
\text { Primary adenocarcinoma } \\
\text { Metastatic adenocarcinoma }\end{array}$ \\
\hline Inverted pattern & Inverted papilloma \\
\hline
\end{tabular}

Micropapillary variant

Lymphoepithelioma-like carcinoma (LELC)

Sarcomatoid carcinoma (carcinosarcoma)

Small-cell carcinoma

Large-cell neuroendocrine carcinoma

Urothelial carcinoma with trophoblastic differentiation

Plasmacytoid variant

Urothelial carcinoma with rhabdoid features

Urothelial carcinoma with clear cells

Lipoid-rich variant

Osteoclast-rich undifferentiated carcinoma

Giant cell carcinoma
Primary site: primary adenocarcinoma, metastatic papillary serous carcinoma from ovary or uterus Metastatic site: ovary, lung, breast, pancreas

Malignant lymphoma

Chronic cystitis

Urothelial cancer with prominent lymphoid stroma

Leiomyosarcoma

Pseudosarcomatous myofibroblastic proliferation

Urothelial carcinoma with pseudosarcomatous stroma

Chronic inflammation

Lymphoma

High-grade urothelial carcinoma with scant cytoplasm

Alveolar rhabdomyosarcoma

Extension from small-cell carcinoma of prostate

Metastatic small-cell carcinoma from lung

High-grade urothelial carcinoma, NOS

Sarcomatoid carcinoma with undifferentiated giant cells Osteoclast-rich undifferentiated carcinoma of bladder

Metastatic germ cell tumor

Plasmacytoma

Lymphoma

Chronic inflammation

Malignant melanoma

Metastatic carcinoma

Rhabdomyosarcoma

Malignant extrarenal rhabdoid tumor

Primary clear cell adenocarcinoma of bladder/urethra

Metastatic renal cell carcinoma

Prostatic carcinoma

Adenocarcinoma with signet ring cell features

Sarcomatoid urothelial carcinoma with heterologous

liposarcomatous differentiation

Pleomorphic giant-cell carcinoma

Sarcomatoid carcinoma with giant cells

Syncytiotrophoblastic giant cells in high grade infiltrating urothelial carcinoma

Scattered reactive stromal giant cells

Choriocarcinoma of the bladder

Urothelial carcinoma with syncytiotrophoblastic

differentiation

Osteoclast-rich undifferentiated carcinoma
Clinical or pathologic significance

Unfavorable prognosis, possibly because of association with high-grade urothelial carcinoma

Limited series show poor response to chemotherapy and radiation

Unfavorable prognosis, possibly because of association with high-grade urothelial carcinoma

Limited data show poor response to chemotherapy

Potential serious diagnostic pitfall in limited samples

Aggressive clinical course with higher frequency of metastasis

Potential diagnostic pitfall in limited samples

Clinical significance unknown, frequently coexists with nested pattern

Potential diagnostic pitfall in limited sampling No known clinical significance in terms of outcome

Invasion may be overcalled

Prognosis: depends on the presence or absence of lamina propria or muscularis propria invasion

High stage, high grade with frequent vascular invasion: poor prognosis

In biopsy lacking muscularis propria, the presence of micropapillary histology should prompt rebiopsy

Poor response to intravesical therapy in $\mathrm{pTa} / \mathrm{pT} 1$ disease:

early cystectomy is advocated by some authors

Patients with pure tumors may be candidates for

chemotherapy alone-possible salvage of bladder

Tumors with predominant LELC may have slightly

favorable prognosis

Tumors with focal LELC have outcome similar to urothelial carcinoma of similar stage

Extremely aggressive clinical course

2-year survival of $28 \%$, median survival 1 year

Some centers may offer different treatment protocols for sarcomatoid carcinoma than urothelial carcinoma or primary sarcoma

High stage at presentation: very poor prognosis

Association with paraneoplastic syndromes

Frequent disseminated metastasis

Response to newer chemotherapy protocols similar to those used in lung tumors

Uniformly poor prognosis, limited cases

May be associated with small-cell carcinoma

Similar therapeutic approach to small-cell carcinoma

Poor prognosis, limited data

Resistance to radiation, limited data

Urine and serum HCG: markers for disease progression

Potential diagnostic pitfall in limited samples

Advanced stage at presentation: poor prognosis

Poor prognosis

Diagnostic pitfall

Prognosis: depends on the stage of tumor

Diagnostic pitfall

Poor prognosis: related to concurrent high-grade, high stage urothelial carcinoma

Poor prognosis and aggressive clinical behavior

Poor prognosis 
Table 7 Immunohistochemical markers associated with urothelial differentiation: particularly in the setting of carcinoma of unknown primary

\begin{tabular}{|c|c|c|}
\hline $\begin{array}{l}\text { Immunhistochemical } \\
\text { marker/s }\end{array}$ & $\begin{array}{c}\text { Range of } \\
\text { positivity (\%) }\end{array}$ & Specificity \\
\hline CK7+/CK20+ & 65 & Common phenotype of pancreatic, biliary, and gastric carcinomas \\
\hline CK7+/CK20- & 37 & $\begin{array}{l}\text { Common phenotype of breast, lung, endometrial, ovarian, thyroid, and salivary gland } \\
\text { carcinomas; also mesothelioma }\end{array}$ \\
\hline CK7-/CK20+ & 3 & Common phenotype of colonic carcinoma, also Merkel and gastric carcinoma \\
\hline CK7-/CK20- & 10 & $\begin{array}{l}\text { Common phenotype of adrenocortical, renal cell, prostatic, hepatocellular and low-grade } \\
\text { neuroendocrine carcinomas }\end{array}$ \\
\hline Uroplakin III & $57-60$ & To date, not reported in other carcinomas \\
\hline Thrombomodulin & $49-69$ & $\begin{array}{l}\text { Expressed in most mesotheliomas and in some carcinomas including a subset of lung, } \\
\text { breast, ovary, squamous cell, and pancreas; useful in differentiating urothelial cancer from } \\
\text { prostate cancer which are thrombomodulin negative }\end{array}$ \\
\hline CK $34 \beta \mathrm{E} 12$ & $65-100$ & $\begin{array}{l}\text { Expressed in a broad spectrum of other carcinomas including squamous cell of any site and } \\
\text { breast }\end{array}$ \\
\hline
\end{tabular}

characterization of the tumors may have diagnostic, therapeutic or prognostic implications significantly impacting management. A recent review has published a treatment algorithm for resectable urothelial carcinoma of the bladder in which variant histology is a stratifying feature. And this information has been incorporated into clinical treatment algorithms for resectable urothelial carcinoma and in the National Comprehensive Cancer Network (NCCN) Clinical Practice Guidelines for Bladder Cancer. ${ }^{8,133}$ It is not uncommon that tumors with divergent or aberrant differentiation show multiple patterns within the same tumor such as sarcomatoid, smallcell, squamous and glandular differentiation. When multiple histologies are encountered, the author usually provides the relative percentage of each of the different components, for example, invasive high-grade urothelial carcinoma (50\%), with squamous $(30 \%)$ and glandular differentiation $(20 \%)$. Many variants are clinically aggressive and may present at metastatic sites in which case the unusual variant histology may not readily facilitate relationship with bladder cancer. Comparison with the bladder primary, if available and/or immunohistochemical support may be necessary. Urothelial carcinomas are positive for high-molecular-weight cytokeratin (65-100\%), p63 (70-92\%), thrombomodulin $(49-69 \%)$ and uroplakin III $(57-60 \%))^{44,134,135}$ In carcinomas of unknown primary when differential cytokeratin 7 and 20 staining is used, urothelial carcinomas are typically cytokeratin 7 and frequently cytokeratin 20-positive.

\section{Disclosure/conflict of interest}

The author declares no conflict of interest.

\section{References}

1 Amin $\mathrm{MB}$, Murphy WM, Reuter VE, et al. A symposium on controversies in the pathology of transitional cell carcinomas of the urinary bladder. Part I. Anat Pathol 1996;1:1-39.
2 Eble JN, Young RH. Carcinoma of the urinary bladder: a review of its diverse morphology. Semin Diagn Pathol 1997;14:98-108.

3 Nigwekar P, Amin MB. The many faces of urothelial carcinoma: an update with an emphasis on recently described variants. Adv Anat Pathol 2008;15:218-233.

4 Young RH, Eble JN. Unusual forms of carcinoma of the urinary bladder. Hum Pathol 1991;22:948-965.

5 Zhai QJ, Black J, Ayala AG, et al. Histologic variants of infiltrating urothelial carcinoma. Arch Pathol Lab Med 2007;131:1244-1256.

6 Eble JN, Epstein JI, Sesterhenn IA. Pathology and Genetics of Tumors of the Urinary System and Male Genital Organs. In: IARC (ed). Vol.: Lyon, France, 2004.

7 Perez-Montiel D, Hes O, Michal M, et al. Micropapillary urothelial carcinoma of the upper urinary tract: clinicopathologic study of five cases. Am J Clin Pathol 2006;126:86-92.

8 Black PC, Brown GA, Dinney CP. The impact of variant histology on the outcome of bladder cancer treated with curative intent. Urol Oncol 2009;27:3-7.

9 Kipp BR, Tyner HL, Campion MB, et al. Chromosomal alterations detected by fluorescence in situ hybridization in urothelial carcinoma and rarer histologic variants of bladder cancer. Am J Clin Pathol 2008;130: $552-559$

10 Budia Alba A, Queipo Zaragoza JA, Perez Ebri ML, et al. Comparative study of pure epidermoid carcinoma of the bladder and transitional cell carcinoma with squamous or mixed differentiated foci. Actas Urol Esp 1999;23:111-118.

11 Hong JY, Choi MK, Uhm JE, et al. Palliative chemotherapy for non-transitional cell carcinomas of the urothelial tract. Med Oncol 2008; e-pub ahead of print.

12 Lopez-Beltran A, Martin J, Garcia J, et al. Squamous and glandular differentiation in urothelial bladder carcinomas. Histopathology, histochemistry and immunohistochemical expression of carcinoembryonic antigen. Histol Histopathol 1988;3:63-68.

13 Ro J, Lapham R, M A. Deceptively bland transitional cell carcinoma of the urinary bladder-further characterization of subtle and diagnostically tracherous patterns of invasion in urothelial neoplasia. Adv Anat Pathol 1997;4:244-251.

14 Young RH, Oliva E. Transitional cell carcinomas of the urinary bladder that may be underdiagnosed. A report of four invasive cases exemplifying the homology between neoplastic and non-neoplastic 
transitional cell lesions. Am J Surg Pathol 1996;20: 1448-1454.

15 Baker PM, Young RH. Radiation-induced pseudocarcinomatous proliferations of the urinary bladder: a report of 4 cases. Hum Pathol 2000;31:678-683.

16 Talbert ML, Young RH. Carcinomas of the urinary bladder with deceptively benign-appearing foci. A report of three cases. Am J Surg Pathol 1989;13: 374-381.

17 Dhall D, Al-Ahmadie H, Olgac S. Nested variant of urothelial carcinoma. Arch Pathol Lab Med 2007;131: 1725-1727.

18 Drew PA, Furman J, Civantos F, et al. The nested variant of transitional cell carcinoma: an aggressive neoplasm with innocuous histology. Mod Pathol 1996;9:989-994.

19 Holmang S, Johansson SL. The nested variant of transitional cell carcinoma-a rare neoplasm with poor prognosis. Scand J Urol Nephrol 2001;35:102-105.

20 Lin O, Cardillo M, Dalbagni G, et al. Nested variant of urothelial carcinoma: a clinicopathologic and immunohistochemical study of 12 cases. Mod Pathol 2003; 16:1289-1298.

21 Murphy WM, Deana DG. The nested variant of transitional cell carcinoma: a neoplasm resembling proliferation of Brunn's nests. Mod Pathol 1992;5: 240-243.

22 Nese N, Kandiloglu AR, Atesci YZ. Nested variant of transitional cell carcinoma with osseous metaplasia of the urinary bladder: a case report and review of published reports. Int J Urol 2007;14:365-367.

23 Oliva E, Young RH. Nephrogenic adenoma of the urinary tract: a review of the microscopic appearance of 80 cases with emphasis on unusual features. Mod Pathol 1995;8:722-730.

24 McKenney JK, Amin MB. The role of immunohistochemistry in the diagnosis of urinary bladder neoplasms. Semin Diagn Pathol 2005;22:69-87.

25 Volmar KE, Chan TY, De Marzo AM, et al. Florid von Brunn nests mimicking urothelial carcinoma: a morphologic and immunohistochemical comparison to the nested variant of urothelial carcinoma. Am J Surg Pathol 2003;27:1243-1252.

26 Huang Q, Chu PG, Lau SK, et al. Urothelial carcinoma of the urinary bladder with a component of acinar/ tubular type differentiation simulating prostatic adenocarcinoma. Hum Pathol 2004;35:769-773.

27 Leroy X, Leteurtre E, De La Taille A, et al. Microcystic transitional cell carcinoma: a report of 2 cases arising in the renal pelvis. Arch Pathol Lab Med 2002;126: 859-861.

28 Young RH, Zukerberg LR. Microcystic transitional cell carcinomas of the urinary bladder. A report of four cases. Am J Clin Pathol 1991;96:635-639.

29 Sari A, Uyaroglu MA, Ermete M, et al. Microcystic urothelial carcinoma of the urinary bladder metastatic to the penis. Pathol Oncol Res 2007;13:170-173.

30 Amin MB, Gomez JA, Young RH. Urothelial transitional cell carcinoma with endophytic growth patterns: a discussion of patterns of invasion and problems associated with assessment of invasion in 18 cases. Am J Surg Pathol 1997;21:1057-1068.

31 Jimenez RE, Keane TE, Hardy HT, et al. pT1 urothelial carcinoma of the bladder: criteria for diagnosis, pitfalls, and clinical implications. Adv Anat Pathol 2000;7:13-25.
32 Jones TD, Zhang S, Lopez-Beltran A, et al. Urothelial carcinoma with an inverted growth pattern can be distinguished from inverted papilloma by fluorescence in situ hybridization, immunohistochemistry, and morphologic analysis. Am J Surg Pathol 2007;31: 1861-1867.

33 Kamat AM, Dinney CP, Gee JR, et al. Micropapillary bladder cancer: a review of the University of Texas M. D. Anderson Cancer Center experience with 100 consecutive patients. Cancer 2007;110:62-67.

34 Johansson SL, Borghede G, Holmang S. Micropapillary bladder carcinoma: a clinicopathological study of 20 cases. J Urol 1999;161:1798-1802.

35 Charfi S, Moussa A, Njim L, et al. Micropapillary bladder carcinoma. Prog Urol 2006;16:607-609.

36 Holmang S, Thomsen J, Johansson SL. Micropapillary carcinoma of the renal pelvis and ureter. J Urol 2006;175:463-466; discussion 466-467.

37 Alvarado-Cabrero I, Sierra-Santiesteban FI, MantillaMorales A, et al. Micropapillary carcinoma of the urothelial tract. A clinicopathologic study of 38 cases. Ann Diagn Pathol 2005;9:1-5.

38 Dhouib RS, Abbes I, Mrad K, et al. Micropapillary transitional cell carcinoma of the urinary bladder: report of two cases. Pathologica 2005; 97:338-340.

39 Munakata S, Tahara H, Kojima K, et al. Micropapillary urothelial carcinoma of the renal pelvis: report of a case and review of the literature. Med Sci Monit 2007;13:CS47-CS52.

40 Amin MB, Ro JY, el-Sharkawy T, et al. Micropapillary variant of transitional cell carcinoma of the urinary bladder. Histologic pattern resembling ovarian papillary serous carcinoma. Am J Surg Pathol 1994;18: 1224-1232.

41 Ylagan LR, Humphrey PA. Micropapillary variant of transitional cell carcinoma of the urinary bladder: a report of three cases with cytologic diagnosis in urine specimens. Acta Cytol 2001;45:599-604.

42 Samaratunga $\mathrm{H}$, Khoo K. Micropapillary variant of urothelial carcinoma of the urinary bladder; a clinicopathological and immunohistochemical study. Histopathology 2004;45:55-64.

43 Regalado JJ. Mixed micropapillary and trophoblastic carcinoma of bladder: report of a first case with new immunohistochemical evidence of urothelial origin. Hum Pathol 2004;35:382-384.

44 Parker DC, Folpe AL, Bell J, et al. Potential utility of uroplakin III, thrombomodulin, high molecular weight cytokeratin, and cytokeratin 20 in noninvasive, invasive, and metastatic urothelial (transitional cell) carcinomas. Am J Surg Pathol 20031;27:1-10.

45 Kamat AM, Gee JR, Dinney CP, et al. The case for early cystectomy in the treatment of nonmuscle invasive micropapillary bladder carcinoma. J Urol 2006;175 (3 Part 1):881-885.

46 Holmang S, Borghede G, Johansson SL. Bladder carcinoma with lymphoepithelioma-like differentiation: a report of 9 cases. J Urol 1998;159:779-782.

47 Gulley ML, Amin MB, Nicholls JM, et al. EpsteinBarr virus is detected in undifferentiated nasopharyngeal carcinoma but not in lymphoepithelioma-like carcinoma of the urinary bladder. Hum Pathol 1995;26:1207-1214.

48 Dinney CP, Ro JY, Babaian RJ, et al. Lymphoepithelioma of the bladder: a clinicopathological study of 3 cases. J Urol 1993;149:840-841. 
49 Amin MB, Ro JY, Lee KM, et al. Lymphoepitheliomalike carcinoma of the urinary bladder. Am J Surg Pathol 1994;18:466-473.

50 Lopez-Beltran A, Luque RJ, Vicioso L, et al. Lymphoepithelioma-like carcinoma of the urinary bladder: a clinicopathologic study of 13 cases. Virchows Arch 2001;438:552-557.

51 Tamas EF, Nielsen ME, Schoenberg MP, et al. Lymphoepithelioma-like carcinoma of the urinary tract: a clinicopathological study of 30 pure and mixed cases. Mod Pathol 2007;20:828-834.

52 Lopez-Beltran A, Pacelli A, Rothenberg HJ, et al. Carcinosarcoma and sarcomatoid carcinoma of the bladder: clinicopathological study of 41 cases. J Urol 1998;159:1497-1503.

53 Wright JL, Black PC, Brown GA, et al. Differences in survival among patients with sarcomatoid carcinoma, carcinosarcoma and urothelial carcinoma of the bladder. J Urol 2007;178:2302-2306; discussion 2307.

54 Sung MT, Wang M, MacLennan GT, et al. Histogenesis of sarcomatoid urothelial carcinoma of the urinary bladder: evidence for a common clonal origin with divergent differentiation. J Pathol 2007;211: $420-430$.

55 Jones EC, Young RH. Myxoid and sclerosing sarcomatoid transitional cell carcinoma of the urinary bladder: a clinicopathologic and immunohistochemical study of 25 cases. Mod Pathol 1997;10:908-916.

56 Acikalin MF, Kabukcuoglu S, Can C. Sarcomatoid carcinoma of the renal pelvis with giant cell tumorlike features: case report with immunohistochemical findings. Int J Urol 2005;12:199-203.

57 Young RH, Wick MR, Mills SE. Sarcomatoid carcinoma of the urinary bladder. A clinicopathologic analysis of 12 cases and review of the literature. Am J Clin Pathol 1988;90:653-661.

58 Torenbeek R, Blomjous CE, de Bruin PC, et al. Sarcomatoid carcinoma of the urinary bladder. Clinicopathologic analysis of 18 cases with immunohistochemical and electron microscopic findings. Am J Surg Pathol 1994;18:241-249.

59 Ikegami H, Iwasaki H, Ohjimi Y, et al. Sarcomatoid carcinoma of the urinary bladder: a clinicopathologic and immunohistochemical analysis of 14 patients. Hum Pathol 2000;31:332-340.

60 Reuter VE. Sarcomatoid lesions of the urogenital tract. Semin Diagn Pathol 1993;10:188-201.

61 Young RH, Wick MR. Transitional cell carcinoma of the urinary bladder with pseudosarcomatous stroma. Am J Clin Pathol 1988;90:216-219.

62 Wick MR, Swanson PE. Carcinosarcomas: current perspectives and an historical review of nosological concepts. Semin Diagn Pathol 1993;10:118-127.

63 Armstrong AB, Wang M, Eble JN, et al. TP53 mutational analysis supports monoclonal origin of biphasic sarcomatoid urothelial carcinoma (carcinosarcoma) of the urinary bladder. Mod Pathol 2009;22: 113-118.

64 Shah SK, Lui PD, Baldwin DD, et al. Urothelial carcinoma after external beam radiation therapy for prostate cancer. J Urol 2006;175:2063-2066.

65 Harik LR, Merino C, Coindre JM, et al. Pseudosarcomatous myofibroblastic proliferations of the bladder: a clinicopathologic study of 42 cases. Am J Surg Pathol 2006;30:787-794.

66 Westfall DE, Folpe AL, Paner GP, et al. Utility of a comprehensive immunohistochemical panel in the differential diagnosis of spindle cell lesions of the urinary bladder. Am J Surg Pathol 2009;33:99-105.

67 Pan CX, Yang XJ, Lopez-Beltran A, et al. c-kit Expression in small cell carcinoma of the urinary bladder: prognostic and therapeutic implications. Mod Pathol 2005;18:320-323.

68 Agoff SN, Lamps LW, Philip AT, et al. Thyroid transcription factor-1 is expressed in extrapulmonary small cell carcinomas but not in other extrapulmonary neuroendocrine tumors. Mod Pathol 2000;13: 238-242.

69 Bex A, Nieuwenhuijzen JA, Kerst M, et al. Small cell carcinoma of bladder: a single-center prospective study of 25 cases treated in analogy to small cell lung cancer. Urology 2005;65:295-299.

70 Sved P, Gomez P, Manoharan M, et al. Small cell carcinoma of the bladder. BJU Int 2004;94:12-17.

71 Abrahams NA, Moran C, Reyes AO, et al. Small cell carcinoma of the bladder: a contemporary clinicopathological study of 51 cases. Histopathology 2005; 46:57-63.

72 Wang W, Epstein JI. Small cell carcinoma of the prostate. A morphologic and immunohistochemical study of 95 cases. Am J Surg Pathol 2008;32:65-71.

73 Choong NW, Quevedo JF, Kaur JS. Small cell carcinoma of the urinary bladder. The Mayo Clinic experience. Cancer 2005;103:1172-1178.

74 Mukesh M, Cook N, Hollingdale AE, et al. Small cell carcinoma of the urinary bladder: a 15-year retrospective review of treatment and survival in the Anglian Cancer Network. BJU Int 2008;103:747-752.

75 Cheng L, Pan CX, Yang XJ, et al. Small cell carcinoma of the urinary bladder: a clinicopathologic analysis of 64 patients. Cancer 2004;101:957-962.

76 Mills SE, Wolfe III JT, Weiss MA, et al. Small cell undifferentiated carcinoma of the urinary bladder. A light-microscopic, immunocytochemical, and ultrastructural study of 12 cases. Am J Surg Pathol 1987; 11:606-617.

77 Mangar SA, Logue JP, Shanks JH, et al. Small-cell carcinoma of the urinary bladder: 10-year experience. Clin Oncol (R Coll Radiol) 2004;16:523-527.

78 Weiss MA. Small-cell carcinoma of the urinary tract. Important prognostic and therapeutic implications. Arch Pathol Lab Med 1993;117:237-238.

79 Wang X, Zhang S, MacLennan GT, et al. Epidermal growth factor receptor protein expression and gene amplification in small cell carcinoma of the urinary bladder. Clin Cancer Res 2007;13:953-957.

80 Terracciano L, Richter J, Tornillo L, et al. Chromosomal imbalances in small cell carcinomas of the urinary bladder. J Pathol 1999;189:230-235.

81 Abbosh PH, Wang M, Eble JN, et al. Hypermethylation of tumor-suppressor gene CpG islands in smallcell carcinoma of the urinary bladder. Mod Pathol 2008;21:355-362.

82 Paner GP, McKenney JK, Epstein JI, et al. Rhabdomyosarcoma of the urinary bladder in adults: predilection for alveolar morphology with anaplasia and significant morphologic overlap with small cell carcinoma. Am J Surg Pathol 2008;32:1022-1028.

83 Bex A, de Vries R, Pos F, et al. Long-term survival after sequential chemoradiation for limited disease small cell carcinoma of the bladder. World J Urol 2009;27:101-106.

84 Sweeney P, Millikan R, Donat M, et al. Is there a therapeutic role for post-chemotherapy retroperitoneal 
lymph node dissection in metastatic transitional cell carcinoma of the bladder? J Urol 2003;169: 2113-2117.

85 Vakar-Lopez F, True LD. How wide is the spectrum of neuroendocrine carcinoma of the urinary bladder? Am J Clin Pathol 2007;128:723-725.

86 Alijo Serrano F, Sanchez-Mora N, Angel Arranz J, et al. Large cell and small cell neuroendocrine bladder carcinoma: immunohistochemical and outcome study in a single institution. Am J Clin Pathol 2007;128:733-739.

87 Evans AJ, Al-Maghrabi J, Tsihlias J, et al. Primary large cell neuroendocrine carcinoma of the urinary bladder. Arch Pathol Lab Med 2002;126:1229-1232.

88 Hailemariam S, Gaspert A, Komminoth $\mathrm{P}$, et al. Primary, pure, large-cell neuroendocrine carcinoma of the urinary bladder. Mod Pathol 1998;11:1016-1020.

89 Martignoni G, Eble JN. Carcinoid tumors of the urinary bladder. Immunohistochemical study of 2 cases and review of the literature. Arch Pathol Lab Med 2003;127:e22-e24.

90 McCabe JE, Das S, Dowling $\mathrm{P}$, et al. Oncocytic carcinoid tumour of the bladder. J Clin Pathol 2005; 58:446-447.

91 Murali R, Kneale K, Lalak N, et al. Carcinoid tumors of the urinary tract and prostate. Arch Pathol Lab Med 2006;130:1693-1706.

92 Dirnhofer S, Koessler P, Ensinger C, et al. Production of trophoblastic hormones by transitional cell carcinoma of the bladder: association to tumor stage and grade. Hum Pathol 1998;29:377-382.

93 Iles RK, Chard T. Human chorionic gonadotropin expression by bladder cancers: biology and clinical potential. J Urol 1991;145:453-458.

94 Iles RK, Jenkins BJ, Oliver RT, et al. Beta human chorionic gonadotrophin in serum and urine. A marker for metastatic urothelial cancer. Br J Urol 1989;64:241-244.

95 Martin JE, Jenkins BJ, Zuk RJ, et al. Human chorionic gonadotrophin expression and histological findings as predictors of response to radiotherapy in carcinoma of the bladder. Virchows Arch A Pathol Anat Histopathol 1989;414:273-277.

96 Sievert K, Weber EA, Herwig R, et al. Pure primary choriocarcinoma of the urinary bladder with longterm survival. Urology 2000;56:856.

97 Rodriguez E, Mathew S, Reuter V, et al. Cytogenetic analysis of 124 prospectively ascertained male germ cell tumors. Cancer Res 1992;52: 2285-2291.

98 Shimada K, Nakamura M, Ishida E, et al. Urothelial carcinoma with plasmacytoid variants producing both human chorionic gonadotropin and carbohydrate antigen 19-9. Urology 2006;68:891.e7-891.e10.

99 Coyne JD, Sim E. Urothelial neoplasia with plasmacytoid morphology. Histopathology 2006;48:200-201.

100 Fritsche HM, Burger M, Denzinger S, et al. Plasmacytoid urothelial carcinoma of the bladder: histological and clinical features of 5 cases. J Urol 2008;180:1923-1927.

101 Gaafar A, Garmendia M, de Miguel E, et al. [Plasmacytoid urothelial carcinoma of the urinary bladder. A study of 7 cases]. Actas Urol Esp 2008;32:806-810.

102 Kohno T, Kitamura M, Akai H, et al. Plasmacytoid urothelial carcinoma of the bladder. Int J Urol 2006; 13:485-486.
103 Mai KT, Park PC, Yazdi HM, et al. Plasmacytoid urothelial carcinoma of the urinary bladder report of seven new cases. Eur Urol 2006;50:1111-1114.

104 Nigwekar P, Tamboli P, Amin MB, et al. Plasmacytoid urothelial carcinoma: detailed analysis of morphology with clinicopathologic correlation in 17 cases. Am J Surg Pathol 2009;33:417-424.

105 Ro JY, Shen SS, Lee HI, et al. Plasmacytoid transitional cell carcinoma of urinary bladder: a clinicopathologic study of 9 cases. Am J Surg Pathol 2008;32:752-757.

106 Sahin AA, Myhre M, Ro JY, et al. Plasmacytoid transitional cell carcinoma. Report of a case with initial presentation mimicking multiple myeloma. Acta Cytol 1991;35:277-280.

107 Sato K, Ueda Y, Kawamura K, et al. Plasmacytoid urothelial carcinoma of the urinary bladder: a case report and immunohistochemical study. Pathol Res Pract 2008;205:189-194.

108 Soylu A, Aydin NE, Yilmaz U, et al. Urothelial carcinoma featuring lipid cell and plasmacytoid morphology with poor prognostic outcome. Urology 2005;65:797.

109 Zhang XM, Elhosseiny A, Melamed MR. Plasmacytoid urothelial carcinoma of the bladder. A case report and the first description of urinary cytology. Acta Cytol 2002;46:412-416.

110 Baldwin L, Lee AH, Al-Talib RK, et al. Transitional cell carcinoma of the bladder mimicking lobular carcinoma of the breast: a discohesive variant of urothelial carcinoma. Histopathology 2005;46:50-56.

111 Kumar S, Kumar D, Cowan DF. Transitional cell carcinoma with rhabdoid features. Am J Surg Pathol 1992;16:515-521.

112 Parwani AV, Herawi M, Volmar K, et al. Urothelial carcinoma with rhabdoid features: report of 6 cases. Hum Pathol 2006;37:168-172.

113 Hoot AC, Russo P, Judkins AR, et al. Immunohistochemical analysis of hSNF5/INI1 distinguishes renal and extra-renal malignant rhabdoid tumors from other pediatric soft tissue tumors. Am J Surg Pathol 2004;28:1485-1491.

114 Gilcrease MZ, Delgado R, Vuitch F, et al. Clear cell adenocarcinoma and nephrogenic adenoma of the urethra and urinary bladder: a histopathologic and immunohistochemical comparison. Hum Pathol 1998;29:1451-1456.

115 Kotliar SN, Wood CG, Schaeffer AJ, et al. Transitional cell carcinoma exhibiting clear cell features. A differential diagnosis for clear cell adenocarcinoma of the urinary tract. Arch Pathol Lab Med 1995; 119:79-81.

116 Oliva E, Amin MB, Jimenez R, et al. Clear cell carcinoma of the urinary bladder: a report and comparison of four tumors of mullerian origin and nine of probable urothelial origin with discussion of histogenesis and diagnostic problems. Am J Surg Pathol 2002;26:190-197.

117 Sun K, Huan Y, Unger PD. Clear cell adenocarcinoma of urinary bladder and urethra: another urinary tract lesion immunoreactive for P504S. Arch Pathol Lab Med 2008;132:1417-1422.

118 Sung MT, Zhang S, MacLennan GT, et al. Histogenesis of clear cell adenocarcinoma in the urinary tract: evidence of urothelial origin. Clin Cancer Res 2008;14:1947-1955. 
119 Sim SJ, Ro JY, Ordonez NG, et al. Metastatic renal cell carcinoma to the bladder: a clinicopathologic and immunohistochemical study. Mod Pathol 1999;12: 351-355.

120 Gupta R, Balzer B, Picken M, et al. Diagnostic implications of transcription factor Pax 2 protein and transmembrane enzyme complex carbonic anhydrase IX immunoreactivity in adult renal epithelial neoplasms. Am J Surg Pathol 2009;33:241-247.

121 Di Como CJ, Urist MJ, Babayan I, et al. p63 Expression profiles in human normal and tumor tissues. Clin Cancer Res 2002;8:494-501.

122 Lane Z, Hansel DE, Epstein JI. Immunohistochemical expression of prostatic antigens in adenocarcinoma and villous adenoma of the urinary bladder. Am J Surg Pathol 2008;32:1322-1326.

123 Leroy X, Gonzalez S, Zini L, et al. Lipoid-cell variant of urothelial carcinoma: a clinicopathologic and immunohistochemical study of five cases. Am J Surg Pathol 2007;31:770-773.

124 Mahadevia PS, Alexander JE, Rojas-Corona R, et al. Pseudosarcomatous stromal reaction in primary and metastatic urothelial carcinoma. A source of diagnostic difficulty. Am J Surg Pathol 1989;13:782-790.

125 Young RH. Spindle cell lesions of the urinary bladder. Histol Histopathol 1990;5:505-512.

126 Peyromaure M, Beuzeboc P, Chekulaev D, et al. Sarcomatoid carcinoma with heterologous osteoid differentiation. Prog Urol 2006;16:378-380.

127 Amir G, Rosenmann E. Osteoclast-like giant cell tumour of the urinary bladder. Histopathology 1990;17:413-418.
128 Garcia Garcia F, Garcia Ligero J, Martinez Diaz F, et al. Bladder carcinoma with osteoclast-type giant cells. A case with a rare presentation. Review of the literature. Actas Urol Esp 2003;27:317-320.

129 Kruger S, Johannisson R, Kausch I, et al. Papillary urothelial bladder carcinoma associated with osteoclast-like giant cells. Int Urol Nephrol 2005;37:61-64.

130 Zukerberg LR, Armin AR, Pisharodi L, et al. Transitional cell carcinoma of the urinary bladder with osteoclast-type giant cells: a report of two cases and review of the literature. Histopathology 1990;17: 407-411.

131 Baydar D, Amin MB, Epstein JI. Osteoclast-rich undifferentiated carcinomas of the urinary tract. Mod Pathol 2006;19:161-171.

132 O'Connor RC, Hollowell CM, Laven BA, et al. Recurrent giant cell carcinoma of the bladder. J Urol 2002;167:1784.

133 Oncology $^{\text {TM }}$ NCPGi. Bladder Cancer. 2007. 1 January 2009 cited. Available athttp://www.nccn.org/professionals/physician_gls/PDF/bladder.pdf.

134 Chuang AY, DeMarzo AM, Veltri RW, et al. Immunohistochemical differentiation of high-grade prostate carcinoma from urothelial carcinoma. Am J Surg Pathol 2007;31:1246-1255.

135 Kunju LP, Mehra R, Snyder M, et al. Prostate-specific antigen, high-molecular-weight cytokeratin (clone 34betaE12), and/or p63: an optimal immunohistochemical panel to distinguish poorly differentiated prostate adenocarcinoma from urothelial carcinoma. Am J Clin Pathol 2006;125:675-681. 